\title{
Thermodynamically Consistent Modeling of Redox-Stable Perovskite Oxides for Thermochemical Energy Conversion and Storage
}

\author{
Kevin J. Albrecht, Gregory S. Jackson, Robert J. Braun* \\ Department of Mechanical Engineering, College of Engineering and Computational Sciences, Colorado School of Mines, 1610 Illinois Street, \\ Golden, CO 80401, USA
}

\begin{abstract}
This paper describes an approach to thermodynamically consistent modeling of perovskite redox cycles for thermochemical energy storage and chemical-looping combustion. Prior modeling approaches to perovskite redox processes do not provide exact closure of the energy balance or thermodynamic consistency for calculating enthalpies and exergies of multiphase solid-gas flows needed in system-level process analysis. The approach documented here implements solid species thermodynamic functions derived from the enthalpies and entropies of reactions including oxidation/reduction and additional point defect reactions. The approach is fundamentally different than the typical approach of using partial molar properties to perform process flow modeling. Coupling process flow modeling to point defect reactions captures complex trends observed for oxygen non-stoichiometry and varying specific heat capacities during reduction and oxidation, maintains thermodynamic consistency between the solid and gas phase species, and thereby enables modeling of flow conservation equations for both the solid and gas phases. The thermodynamic model is fit to reported measurements for a highly reducible perovskite, strontium-doped calcium manganite $\left(\mathrm{Ca}_{0.6} \mathrm{Sr}_{0.4} \mathrm{MnO}_{3-\delta}\right)$, and then demonstrated through equilibrium thermodynamic calculations in process energy and exergy balances. Energetic and exergetic analyses for $\mathrm{Ca}_{0.6} \mathrm{Sr}_{0.4} \mathrm{MnO}_{3-\delta}$ redox cycles are presented for thermochemical energy storage and chemical-looping combustion systems where component exergy destructions are calculated. The model predicts roundtrip thermochemical energy storage efficiencies with $\mathrm{Ca}_{0.6} \mathrm{Sr}_{0.4} \mathrm{MnO}_{3-\delta}$ as high as $89 \%$ and $63 \%$ by first and second law analyses, respectively. The chemical-looping combustion of methane using $\mathrm{Ca}_{0.6} \mathrm{Sr}_{0.4} \mathrm{MnO}_{3-\delta}$ indicates first and second law efficiencies up to $90 \%$ and $66 \%$, respectively. The modeling approach is used to explore trends in performance with operating conditions for both redox cycles thereby enabling new insight regarding design trade-offs for these emerging energy storage and conversion cycles.
\end{abstract}

Keywords: perovskite, redox cycles, exergy, point defect model, chemical looping, thermochemical energy storage

\footnotetext{
${ }^{*}$ Corresponding author. Tel.: + 303273 3055; fax: + 3032733602 .

Email addresses: kalbrech@mymail .mines . edu (Kevin J. Albrecht), gs jackso@mines . edu (Gregory S. Jackson), rbraun@mines . edu (Robert J. Braun)
} 


\section{Introduction}

1 Oxide-based perovskites, with the chemical composition $\mathrm{ABO}_{3-\delta}$ where $\mathrm{A}$ and $\mathrm{B}$ are cations that may have multiple 2 valence states, can exhibit significant swings in oxygen non-stoichiometry ( $\delta$ approaching as high as 0.5$)$ through 3 reaction with gas phase oxygen.

$$
\mathrm{ABO}_{3-\delta} \rightleftharpoons \mathrm{ABO}_{3-\delta-\Delta \delta}+\frac{1}{2} \Delta \delta \mathrm{O}_{2}
$$

${ }_{4}$ Variations in $\delta$ are both functions of temperature $(T)$ and gas phase oxygen partial pressure $\left(p_{\mathrm{O}_{2}}\right)$. By appropriately 5 selecting the A and B cations, often with some amount of doping on one or both of the sites, perovskite materials can be 6 tailored to maintain their perovskite crystalline structure throughout redox cycles with large swings in $\delta$. This tolerance 7 for wide swings in $\delta$ makes perovskites attractive as oxygen carriers in redox processes including chemical-looping 8 combustion $[1,2,3]$, thermochemical chemical energy storage with solid particulate media $[4,5,6]$, and water and/or 9 carbon dioxide reduction using reducible oxides for solar fuel production [7, 8, 9]. Combined systems of chemical1o looping combustion and thermochemical energy storage have been studied [10] which could use a perovskite oxide 11 material as well. These processes require perovskite compositions that can provide large changes in $\delta$ with favorable 12 thermodynamics, fast reaction kinetics, and structural integrity through changes in $p_{\mathrm{O}_{2}}$ and/or $T$.

13 Several perovskite compositions, typically with doping of the primary cation on the A- and/or B- sites in the 14 crystal structure, have demonstrated wide swings in $\delta$ with changes in $p_{\mathrm{O}_{2}}$ and/or $T$ necessary for redox cycles. These 15 promising redox properties have motivated many recent studies on various perovskite compositions for different redox 16 applications. Promising results for chemical-looping have been reported for B-site doped $\mathrm{CaMnO}_{3-\delta} \mathrm{and} \mathrm{CaFeO}_{3-\delta}$ 17 including $\mathrm{CaTi}_{\mathrm{x}} \mathrm{Mn}_{1-\mathrm{x}} \mathrm{O}_{3-\delta}[1,11,12]$, and $\mathrm{CaMg}_{\mathrm{x}} \mathrm{Mn}_{1-\mathrm{x}} \mathrm{O}_{3-\delta}[1,13,14], \mathrm{CaFe}_{\mathrm{x}} \mathrm{Mn}_{1-\mathrm{x}} \mathrm{O}_{3-\delta}[1]$, and $\mathrm{CaTi}_{\mathrm{x}} \mathrm{Fe}_{1-\mathrm{x}} \mathrm{O}_{3-\delta}$ 18 [15]. These studies have focused primarily on the doped $\mathrm{CaMnO}_{3-\delta}$ compositions due to their earth-abundant cations 19 and potential for low cost in chemical-looping combustion. Recent studies for oxide-based redox cycles to split $\mathrm{H}_{2} \mathrm{O}$ 20 and $\mathrm{CO}_{2}$ have explored alternative perovskites containing $\mathrm{La}$ and $\mathrm{Sr}$ including $\mathrm{La}_{1-\mathrm{y}} \mathrm{Sr}_{\mathrm{y}} \mathrm{MnO}_{3-\delta}[8,16], \mathrm{La}_{1-\mathrm{y}} \mathrm{Sr}_{\mathrm{y}} \mathrm{FeO}_{3-\delta}$ 21 [16], and $\mathrm{La}_{1-\mathrm{y}} \mathrm{Sr}_{\mathrm{y}} \mathrm{Al}_{\mathrm{x}} \mathrm{Mn}_{1-\mathrm{x}} \mathrm{O}_{3-\delta}$ [7]. The La-based perovskites demonstrate higher stability at high $T$ (>1200 K) than 22 their Ca-based analogues, which makes La-based perovskites more attractive for solar-driven $\mathrm{H}_{2} \mathrm{O}$ and $\mathrm{CO}_{2}$ splitting 23 for renewable thermochemical fuel production. More recent studies have explored similar La-based perovskites, such 24 as $\mathrm{La}_{1-\mathrm{y}} \mathrm{Sr}_{\mathrm{y}} \mathrm{Co}_{\mathrm{x}} \mathrm{Mn}_{1-\mathrm{x}} \mathrm{O}_{3-\delta}$ and $\mathrm{La}_{1-\mathrm{y}} \mathrm{Sr}_{\mathrm{y}} \mathrm{Co}_{\mathrm{x}} \mathrm{Fe}_{1-\mathrm{x}} \mathrm{O}_{3-\delta}$, in redox cycles at $T>1200 \mathrm{~K}$ for thermochemical energy storage 25 [5]. While these La-containing compositions have high redox energy storage capacity, they are not cost-effective at 26 lower $T$ where lower storage capacities require more cost-effective compositions with earth-abundant cations.

27 Selecting perovskite compositions based on redox properties (thermodynamics and kinetics) for these applications 28 remains largely a matter of experimental investigations to measure properties with some guidance based on cation 29 electronic structure [17]. However, recent advances in atomistic modeling suggest that computational approaches 
1 may provide significant guidance in the future [18]. The eventual implementation of perovskite redox cycles for any 2 of these applications will require appropriate modeling approaches and tools not only to select materials but also to 3 accurately evaluate potential performance for the broad range of compositions amenable for a particular application. 4 Thus, accurate and consistent thermodynamic modeling approaches allowing for energy and exergy analyses including 5 the $\mathrm{O}_{2}$ in the gas phase are critical for reliable design studies to assess the feasibility of these redox processes.

- Many prior efforts to express the thermodynamics of reducible oxide materials as a working fluid, have been 7 formulated with an expression for the solid enthalpy $\bar{h}_{\mathrm{s}}$ in the form of

$$
\bar{h}_{\mathrm{s}}=\int_{\delta_{\circ}, T_{\circ}}^{\delta, T_{\circ}} \Delta H_{\mathrm{O}} d \delta+\int_{\delta, T_{\circ}}^{\delta, T} \bar{c}_{\mathrm{p}} d T
$$

$s$ where the first integral in terms of oxygen non-stoichiometry $\delta$ represents the chemical energy. The partial molar en- thalpy change of oxygen $\left(\Delta H_{\mathrm{O}}\right)$, which is typically obtained from coulometric titration or thermogravimetric analysis, 10 evaluates the chemical reaction term based on the assumption that the reaction enthalpy change depends only on the 11 change in $\delta[17,19]$. The second term in Eq. (2) assumes $\bar{c}_{\mathrm{p}}$ to be either constant or at most a function of only $T$. This 12 common approach to calculate $\bar{h}_{\mathrm{s}}$ lacks the necessary thermodynamic consistency for energetic or exergetic analysis 13 of processes/systems due to the following reason. Molar specific heat $\bar{c}_{\mathrm{p}}$ does depend on $\delta$ as well as $T$ [20]. If the 14 functional dependencies for $\bar{c}_{\mathrm{p}}$ on $\delta$ and $T$ are implemented in the sensible term, the integration for $\bar{h}_{\mathrm{s}}$ in Eq. (2) will 15 be incorrectly path-dependent unless $\Delta H_{\mathrm{O}}$ has a compensating dependence on $\delta$ and $T$.

16 The novelty of the present work is that it develops a material model that has consistency with the gas phase reacting 17 species and ensures path independence of the thermodynamic functions. Without such a material model, results will 18 be dependent on how the integration for $\bar{h}_{\mathrm{s}}$, in Eq. (2), is performed. Furthermore, to properly account for process 19 gas heating requirements and solid heat exchange in process flow modeling, the distribution of energy between the 20 solid and gas phases during oxidation and reduction in the redox cycle needs to be correctly resolved. A practical use 21 of perovskite oxide property characteristics found in the extant literature is to apply them in process modeling and 22 design calculations for reactors and energy conversion and storage systems. These properties are typically established ${ }_{23}$ via highly idealized isothermal calorimetry experiments where the solid/gas products and reactants are at the same 24 temperature. However, in a real system, the reacting solids and gases are often not at the same temperature, and thus ${ }_{25}$ correctly capturing the sensible contributions requires a model which is thermodynamically consistent between the 26 phases. This is in contrast to the highly idealized isothermal calorimetry experiments where products and reactants ${ }_{27}$ are at the same temperature. This paper illustrates the impact of this consistency through calculations presented herein ${ }_{28}$ which show that energy storage in perovskite materials can be diminished through providing a surplus of oxidant.

The necessary dependency of $\Delta H_{\mathrm{O}}$ on $\delta$ and $T$ can be derived from the fact that $\Delta H_{\mathrm{O}}$ incorporates enthalpies of so more than one reaction whose fractional contributions can vary with $\delta$ and $T$. Thus, $\Delta H_{\mathrm{O}}$ can depend on $\delta$ and $T$ 
1 even if the individual reactions, oxidation/reduction and other point defect reactions do not. Fundamental studies of 2 perovskite thermodynamics in solid state ionics often consider detailed point defect reactions [21, 22, 23], but these 3 detailed reaction thermodynamics have yet to be coupled to system-level models for process analysis. Beyond properly ${ }_{4}$ accounting for the solid-gas energy partitioning, these detailed point-defect models are important for predicting the 5 defect concentrations in the material. Point defect concentrations are important to consider when surface reactions and 6 bulk transport are incorporated into the material models because surface reaction rates and bulk-phase ion transport 7 depend strongly on surface and bulk defect concentrations, respectively. In addition, gradients in defect concentrations s can lead to electrostatic potential gradients in the material which also impact surface reactions and transport [24]. 9 Thus, an improved modeling approach for the oxide-based perovskites will facilitate more accurate simulation tools 10 for designing redox cycles in energy conversion and/or storage applications.

11 The thermodynamics of point defect models for perovskite oxide materials have been discussed in detail by many 12 researchers. Mizusaki et al. [25] derived the ideal solution model of a perovskite oxide material relating statistical 13 thermodynamics, point defect reactions, and partial molar quantities. More recently, Rørmark et al. [26] and Bakken 14 et al. [27] compared measurable heats of reaction through adiabatic calorimetry and non-stoichiometry data in com15 parison to the thermodynamics and non-stoichiometry of several point defect models. Although the coupling of redox 16 thermodynamics and point defect models have been well studied, a methodology for thermodynamically consistent 17 modeling of the gas-solid reactions necessary for process energetic and exergetic analysis of multiphase solid-gas 18 cycles has not been presented to the authors' knowledge.

19 This paper presents such a modeling approach and provides functions for calculating the enthalpy and entropy of 2o the solid in reference to the oxygen in the gas phase with thermodynamic parameters obtained from a point defect ${ }_{21}$ model. The thermodynamic property functions are verified against alternative methods of calculating the partial molar 22 enthalpy and entropy change of oxygen from the gas phase to solid phase. Energy and exergy analyses are applied ${ }_{23}$ to case studies using $\mathrm{Ca}_{0.6} \mathrm{Sr}_{0.4} \mathrm{MnO}_{3-\delta}$ for thermochemical energy storage and for chemical-looping combustion. The 24 calculations use recent thorough measurements on strontium-doped $\mathrm{CaMnO}_{3-\delta}$ [22] as a basis for analyzing the redox ${ }_{25}$ properties for both thermochemical energy storage and chemical-looping combustion. The results demonstrate exact 26 closure of the energy, entropy, and exergy balances. Additionally, exergy flows and breakdowns of exergy destruction ${ }_{27}$ are provided for each system statepoint and component to show the value of the property formulations developed ${ }_{28}$ herein. The authors hope that this study will facilitate the connections between advances in perovskite material dis29 covery and development of redox cycles for advances in relevant energy conversion and chemical processes. 


\section{2. Thermodynamic Property Model}

2 In order to develop the model and define the thermodynamic functions, a material must be selected with known ${ }_{3}$ defect reactions and thermodynamics parameters. Strontium-doped calcium manganate $\left(\mathrm{Ca}_{0.6} \mathrm{Sr}_{0.4} \mathrm{MnO}_{3-\delta}\right)$ has well4 defined properties [22], which make it potentially attractive for chemical-looping combustion [1] as well as concen5 trating solar power (CSP) thermochemical energy storage [4]. However, the thermodynamics of strontium doped 6 $\mathrm{CaMnO}_{3-\delta}$ are not favorable for solar fuel production because the heats of reduction are not high enough to drive $\mathrm{H}_{2} \mathrm{O}$ 7 and/or $\mathrm{CO}_{2}$ splitting at kinetically favorable temperatures [7]. All the same, $\mathrm{Ca}_{0.6} \mathrm{Sr}_{0.4} \mathrm{MnO}_{3-\delta}$ is well-suited for the s development of the thermodynamic modeling methodology since phase changes (between orthorombic, tetragonal,

9 and cubic crystalline structures) occur outside of the particular $T\left(500^{\circ} \mathrm{C}\right.$ to $\left.1000^{\circ} \mathrm{C}\right)$ and $p_{\mathrm{O}_{2}}\left(10^{0}\right.$ to $10^{-5}$ atm $)$ range 10 of interest [22]. Although phase changes could be incorporated into the model, that complicates the initial develop11 ment and will not be presented in this study. The point defect model and thermodynamics implemented are based on 12 the work of Goldyreva et al. [22], which assumes two defect reactions ( $k \in$ ox, dis) consisting of an oxygen incor13 poration and manganese disproportionation, reactions (3) and (4) respectively. The point defect reactions have been 14 written using Kröger-Vink notation where the chemical symbol denotes the species $(\mathrm{O}=$ oxygen, Mn $=$ manganese, ${ }_{15} \mathrm{Ca}=$ calcium, and $\mathrm{V}=$ vacancy), subscript denotes the lattice site of the species, and superscript denotes the charge $16(\bullet(+1), \times(0), \prime(-1))$ relative to a neutral lattice.

$$
\frac{1}{2} \mathrm{O}_{2(\mathrm{~g})}+\mathrm{V}_{\mathrm{O}}^{\bullet \bullet}+2 \mathrm{Mn}_{\mathrm{Mn}}^{\prime} \rightleftharpoons \mathrm{O}_{\mathrm{O}}^{\times}+2 \mathrm{Mn}_{\mathrm{Mn}}^{\times}
$$

17

$$
2 \mathrm{Mn}_{\mathrm{Mn}}^{\times} \rightleftharpoons \mathrm{Mn}_{\mathrm{Mn}}^{\prime}+\mathrm{Mn}_{\mathrm{Mn}}^{\bullet}
$$

18 The oxygen incorporation reaction (Eq. (3)) brings oxygen from the gas phase into lattice oxide vacancies. The 19 reaction requires dissociation of $\mathrm{O}_{2}$ from the gas phase on the perovskite surface and subsequent reaction of the 2o resulting $\mathrm{O}$ atoms with an oxygen vacancy $\left(\mathrm{V}_{\mathrm{O}}^{\bullet \bullet}\right)$, and two manganese polarons $\left(\mathrm{Mn}_{\mathrm{Mn}}^{\prime}\right)$ to compensate the $2+$ charge 21 of the vacancy. The overall reaction produces an oxide in the lattice $\left(\mathrm{O}_{\mathrm{O}}^{\times}\right)$and two fully oxidized manganese cations $22\left(\mathrm{Mn}_{\mathrm{Mn}}^{\times}\right)$. The disproportionation reaction (Eq. (4)) results in two manganese cations changing oxidation states. To 23 maintain electroneutrality in the disproportionation reaction, one Mn must reduce oxidation state and the other must 24 increase its oxidation state. The set of point defect reactions is fundamentally different from the global expression 25 (Eq. (1)) through the consideration of electroneutrality and the oxidation state of the B-site cation. This approach 26 allows for the model to capture observed non-linear trends in oxygen non-stoichiometry $\delta$ with respect to $\ln \left(p_{\mathrm{O}_{2}}\right)$. 27 Although additional point defect reactions could be included, such as Schottky and Frenkel reactions, the redox and 28 disproportionation reactions are sufficient, as shown below, to describe the trends in the data for $\mathrm{Ca}_{0.6} \mathrm{Sr}_{0.4} \mathrm{MnO}_{3-\delta}$, ${ }_{29}$ which suggests that the concentration of other defects such as cation vacancies $\left(\mathrm{V}_{\mathrm{Ca}}^{\prime \prime}\right)$ and interstitials $\left(\mathrm{Ca}_{\mathrm{I}}^{\bullet \bullet}\right)$ are 
1 negligible.

2 The partial pressure based equilibrium constant $\left(K_{\mathrm{p}, k}\right)$ for both the incorporation and disproportionation reactions ${ }_{3}$ can be calculated from the standard enthalpy $\left(\Delta H_{k}^{\circ}\right)$ and entropy $\left(\Delta S_{k}^{\circ}\right)$ of reaction $\left(\Delta G_{k}^{\circ}=\Delta H_{k}^{\circ}-T \Delta S_{k}^{\circ}\right)$, which are 4 related to the defect site concentrations.

$$
\begin{gathered}
K_{\mathrm{p}, \mathrm{ox}}=\exp \left(\frac{-\Delta G_{\mathrm{Ox}}^{\circ}}{R T}\right)=\frac{\left[\mathrm{O}_{\mathrm{O}}^{\times}\right]_{\mathrm{L}}\left[\mathrm{Mn}_{\mathrm{Mn}}^{\times}\right]_{\mathrm{L}}^{2}}{\left[\mathrm{~V}_{\mathrm{O}}^{\bullet \bullet}\right]_{\mathrm{L}}\left[\mathrm{Mn}_{\mathrm{Mn}}^{\prime}\right]_{\mathrm{L}}^{2} p_{\mathrm{O}_{2}}^{1 / 2}} \\
K_{\mathrm{p}, \text { dis }}=\exp \left(\frac{-\Delta G_{\mathrm{dis}}^{\circ}}{R T}\right)=\frac{\left[\mathrm{Mn}_{\mathrm{Mn}}^{\prime}\right]_{\mathrm{L}}\left[\mathrm{Mn}_{\mathrm{Mn}}^{\circ}\right]_{\mathrm{L}}}{\left[\mathrm{Mn}_{\mathrm{Mn}}^{\times}\right]_{\mathrm{L}}^{2}}
\end{gathered}
$$

- The notation developed by Kee et al. [24] is implemented here where the site concentrations $\left(\left[X_{i}\right]_{\mathrm{L}}\right)$ are related to the 7 molar concentrations $\left(\left[X_{i}\right]\right)$ through the molar volume $\left(V_{\mathrm{m}}\right)$ as $\left[X_{i}\right]_{\mathrm{L}}=V_{\mathrm{m}}\left[X_{i}\right]$. The reaction equilibrium equations can ${ }_{8}$ be coupled with the site (Eqns. (7), (8), and (9)) and electroneutrality (Eq. (10)) constraints to give a system of six 9 equations with six unknowns capable of being solved for the equilibrium defect site concentrations at specified $T$ and

10 $p_{\mathrm{O}_{2}}$. The A-site lattice constraint (Eq. (7)) required that the site concentration of calcium and strontium dopant on the 11 A-site sum to unity. The B-site (Eq. (8)) lattice constraint requires that the site fraction of manganese in all valance 12 states sum to unity. The O-site (Eq. (9)) constraint requires that the site fraction of oxygen and oxygen vacancies sum 13 to three due to the three oxygen atoms in the perovskite molar unit. Finally, the electroneutrality constraint (Eq. (10)) ${ }_{14}$ requires that the net charge of all the point defects vanish.

$$
1=\left[\mathrm{Ca}_{\mathrm{Ca}}^{\times}\right]_{\mathrm{L}}+\left[\mathrm{Sr}_{\mathrm{Ca}}^{\times}\right]_{\mathrm{L}}
$$

15

$$
1=\left[\mathrm{Mn}_{\mathrm{Mn}}^{\times}\right]_{\mathrm{L}}+\left[\mathrm{Mn}_{\mathrm{Mn}}^{\bullet}\right]_{\mathrm{L}}+\left[\mathrm{Mn}_{\mathrm{Mn}}^{\prime}\right]_{\mathrm{L}}
$$

16

$$
3=\left[\mathrm{V}_{\mathrm{O}}^{\bullet \bullet}\right]_{\mathrm{L}}+\left[\mathrm{O}_{\mathrm{O}}^{\times}\right]_{\mathrm{L}}
$$

17

$$
2\left[\mathrm{~V}_{\mathrm{O}}^{\bullet \bullet}\right]_{\mathrm{L}}+\left[\mathrm{Mn}_{\mathrm{Mn}}^{\bullet}\right]_{\mathrm{L}}=\left[\mathrm{Mn}_{\mathrm{Mn}}^{\prime}\right]_{\mathrm{L}}
$$

18 The system of equations was solved for various $T$ and $p_{\mathrm{O}_{2}}$ (Fig. 1) based on the fitted enthalpies and entropies of 19 reaction from the work of Goldyreva et al. [22] (Table 1). All modeling results presented have been obtain though 2o numerical solution using Engineering Equation Solver (EES) software [28]. Physical properties of gas phase species ${ }_{21}$ were obtained from ideal gas property calls.

\section{2.1. Species Enthalpy}

${ }_{23}$ The enthalpies of the individual reactions are assumed to be independent of temperature, and are related to the ${ }_{24}$ species enthalpies within the solid as follows: 


$$
\Delta H_{\mathrm{OX}}^{\circ}=\bar{h}_{\mathrm{O}_{\mathrm{O}}^{\times}}(T)+2 \bar{h}_{\mathrm{Mn}_{\mathrm{Mn}}^{\times}}(T)-\frac{1}{2} \bar{h}_{\mathrm{O}_{2(\mathrm{~g})}}(T)
$$

$$
-\bar{h}_{\mathrm{V}_{\ddot{O}}}(T)-2 \bar{h}_{\mathrm{Mn}_{\mathrm{Mn}}^{\prime}}(T)
$$

1

$$
\Delta H_{\mathrm{dis}}^{\circ}=\bar{h}_{\mathrm{Mn}_{\mathrm{Mn}}^{\prime}}(T)+\bar{h}_{\mathrm{Mn}_{\mathrm{Mn}}}(T)-2 \bar{h}_{\mathrm{Mn}_{\mathrm{Mn}}^{\times}}(T) .
$$

2 Here species enthalpies include the formation and sensible components $\left(\bar{h}_{i}=\bar{h}_{\mathrm{f}, i}^{\circ}+\int_{T_{\mathrm{o}}}^{T} \bar{c}_{\mathrm{p}, i}(T) d T\right)$. The species ${ }_{3} \mathrm{Mn}_{\mathrm{Mn}}^{\times}$and $\mathrm{V}_{\mathrm{O}}^{\bullet \bullet}$ are set as the standard state with their enthalpy of formation set to zero. Additionally, the enthalpy

${ }_{4}$ of the charge disproportionation reaction is taken to be equally split between the two manganese oxidation states s $\left(\right.$ i.e., $\left.\bar{h}_{\mathrm{f}, \mathrm{Mn}}^{\circ}{ }_{\mathrm{Mn}}^{\circ}=\bar{h}_{\mathrm{f}, \mathrm{Mn} n_{\mathrm{Mn}}^{\circ}}^{\circ}\right)$ by convention, which results in the following equations

$$
\begin{aligned}
& \Delta H_{\mathrm{ox}}^{\circ}=\bar{h}_{\mathrm{f}, \mathrm{O}_{\mathrm{O}}^{\times}}^{\circ}+\int_{T_{\circ}}^{T} \bar{c}_{\mathrm{p}, \mathrm{O}_{\mathrm{O}}^{\times}}(T) d T+2 \int_{T_{\circ}}^{T} \bar{c}_{\mathrm{p}, \mathrm{Mn}} \times \mathrm{Mn}^{\times}(T) d T-\frac{1}{2} \bar{h}_{\mathrm{O}_{2(\mathrm{~g})}}(T)-2\left(\bar{h}_{\mathrm{f}, \mathrm{Mn}_{\mathrm{Mn}}^{\circ}}+\int_{T_{\circ}}^{T} \bar{c}_{\mathrm{p}, \mathrm{Mn}_{\mathrm{Mn}}^{\prime}}(T) d T\right) \\
& \Delta H_{\mathrm{dis}}^{\circ}=2\left(\bar{h}_{\mathrm{f}, \mathrm{Mn}}^{\circ}+\int_{T_{\circ}}^{T} \bar{c}_{\mathrm{p}, \mathrm{Mn}_{\mathrm{Mn}}^{\prime}}(T) d T\right)
\end{aligned}
$$

- Since the enthalpies of reaction are taken to be independent of temperature, the relation $\sum_{i} v_{k, i} \bar{c}_{\mathrm{p}, i}(T)=0$ holds and 7 the two equations can be used to calculate the values of the two unknowns $\bar{h}_{\mathrm{f}, \mathrm{O}_{\mathrm{O}}^{\times}}^{\circ}$ and $\bar{h}_{\mathrm{f}, \mathrm{Mn}}^{\circ}$ as follows,

$$
\begin{gathered}
\Delta H_{\mathrm{oX}}^{\circ}=\bar{h}_{\mathrm{f}, \mathrm{O}_{\mathrm{O}}^{\times}}^{\circ}-\frac{1}{2} \bar{h}_{\mathrm{O}_{2(\mathrm{~g})}}^{\circ}\left(T_{\mathrm{o}}\right)-2 \bar{h}_{\mathrm{f}, \mathrm{Mn}_{\mathrm{Mn}}^{\circ}}^{\circ} \\
\Delta H_{\mathrm{dis}}^{\circ}=2 \bar{h}_{\mathrm{f}, \mathrm{Mn}_{\mathrm{Mn}}^{\circ}}^{\circ}
\end{gathered}
$$

9 The enthalpy of formation of the point defects can then be defined as,

10

$$
\bar{h}_{\mathrm{f}, \mathrm{O}_{\mathrm{O}}^{\times}}^{\circ}=\frac{1}{2} \bar{h}_{\mathrm{O}_{2(\mathrm{~g})}}^{\circ}\left(T_{\circ}\right)+\Delta H_{\mathrm{ox}}^{\circ}+\Delta H_{\mathrm{dis}}^{\circ}
$$

$$
\bar{h}_{\mathrm{f}, \mathrm{Mn}}^{\circ}=\bar{h}_{\mathrm{f}, \mathrm{Mn}}^{\circ} \mathrm{Mn}^{\circ}=\frac{1}{2} \Delta H_{\mathrm{dis}}^{\circ} .
$$


1 From the enthalpy of reaction being independent of temperature, the specific heat of manganese is independent of the 2 oxidation state and the specific heat of the oxygen vacancy is zero. The final relation suggests that the specific heat ${ }_{3}$ of the oxygen in the lattice is the same as the oxygen in the gas phase. The only remaining unknowns are the values 4 of the specific heat of the individual components. Based on Debye crystal statistical thermodynamics [29], the upper ${ }_{5}$ temperature limit of the molar specific heat capacity $\left(\bar{c}_{\mathrm{p}}\right)$ should be $\left(15-3\left[\mathrm{~V}_{\mathrm{O}}^{\bullet \bullet}\right]_{\mathrm{L}}\right)$ where all of the individual atoms 6 in the solid solution are assumed to have a specific heat capacity of $3 R$. However, since the point defect model fits are 7 performed against a temperature independent enthalpy of reaction, the reducible oxygen in the lattice $\left(\left[\mathrm{V}_{\mathrm{O}}^{\bullet \bullet}\right]_{\mathrm{L}}<0.5\right)$ 8 is taken to have the same specific heat as the gas phase oxygen for thermodynamic consistency. Although this results 9 in a specific heat capacity slightly below the statistical limit, it accurately reproduces experimental data.

$$
\bar{h}_{\mathrm{O}_{\mathrm{O}}^{\times}}(T)=\frac{1}{2} \bar{h}_{\mathrm{O}_{2(\mathrm{~g})}}\left(T_{\circ}\right)+\Delta H_{\mathrm{ox}}^{\circ}+\Delta H_{\mathrm{dis}}^{\circ}+\frac{5}{2} \frac{3 R}{\left[\mathrm{O}_{\mathrm{O}}^{\times}\right]_{\mathrm{L}}}\left(T-T_{\circ}\right)
$$$$
+\frac{1}{2} \frac{\frac{1}{2}-\left[\mathrm{V}_{\mathrm{O}}^{\bullet \bullet}\right]_{\mathrm{L}}}{\left[\mathrm{O}_{\mathrm{O}}^{\times}\right]_{\mathrm{L}}}\left(\bar{h}_{\mathrm{O}_{2(\mathrm{~g})}}(T)-\bar{h}_{\mathrm{O}_{2(\mathrm{~g})}}^{\circ}\left(T_{\mathrm{o}}\right)\right)
$$

10

11

12

$$
\bar{h}_{\mathrm{V}_{\mathrm{O}}}(T)=0
$$

$$
\bar{h}_{\mathrm{Mn}_{\mathrm{Mn}}^{\times}}(T)=\bar{h}_{\mathrm{Ca}_{\mathrm{Ca}}^{\times}}(T)=\bar{h}_{\mathrm{Sr}_{\mathrm{Ca}}^{\times}}(T)=3 R\left(T-T_{\circ}\right)
$$

13 The total enthalpy of the solid on a mass basis can then be expressed as,

$$
h_{\mathrm{s}}\left(T,[\mathbf{X}]_{\mathrm{L}}\right)=\frac{1}{M\left(\left[\mathrm{~V}_{\mathrm{O}}^{\bullet \bullet}\right]_{\mathrm{L}}\right)} \sum_{i}\left[X_{i}\right]_{\mathrm{L}} \bar{h}_{i}(T)
$$

14 using the enthalpy expressions from above and a molar mass $(M)$ which is a function of the oxygen vacancy con15 centration. A plot of the total enthalpy of the solid for variations in $T$ and $p_{\mathrm{O}_{2}}$ where the point defect model has 16 been equilibrated is given in Fig. 2. Lines of constant $T$ are shown to have a greater negative slope with increasing $17 T$ and concave up, which is due to the increased material endothermic reduction observed at higher $T$ and reduced ${ }_{18} p_{\mathrm{O}_{2}}$. The difference between any two points on the plot represents thermal energy released by oxidation with ambient 19 temperature oxygen gas.

20 Low temperature $\bar{c}_{\mathrm{p}}$ data is available for undoped calcium manganite [20], and can be used to verify the current 21 use of the high temperature limit of the Debye crystal. $\bar{c}_{\mathrm{p}}$ can be evaluated from the enthalpy functions by the partial 22 derivative with respect to temperature $\left(\bar{c}_{\mathrm{p}}=\left.\frac{\partial \bar{h}_{\mathrm{s}}}{\partial T}\right|_{\left[X_{i}\right]_{\mathrm{L}}}\right)$, numerically evaluated. A comparison of the model predicted ${ }_{23}$ specific heat capacity to the experimental data for the fully oxidized state $\left(\mathrm{CaMnO}_{3-\delta}\right)$ reveals values of 120.7 and 
$1123.7 \mathrm{~kJ} \mathrm{kmol}^{-1} \mathrm{~K}^{-1}$, respectively. Additionally, for a reduced state $\left(\mathrm{CaMnO}_{2.562}\right)$ the model predicted and experi2 mental values are 112.6 and $113.3 \mathrm{~kJ} \mathrm{kmol}^{-1} \mathrm{~K}^{-1}$, respectively. This result supports the use of the Debye crystal high 3 temperature limit of $\bar{c}_{\mathrm{p}}$ with the reducible half mole of oxygen evaluated at the gas phase specific heat to maintain

${ }_{4}$ thermodynamic consistency. This result represents an improvement over existing approaches which assume a constant

${ }_{5} \bar{c}_{\mathrm{p}}$ that can impose errors of up to $10 \%$ in model results (due to $\bar{c}_{\mathrm{p}}$ variations with $\delta$ ) for the energy required to change 6 the temperature of a reduced perovskite. It becomes important to separate the true sensible component of the solid 7 material in the case of thermochemical energy storage because the stored material could potentially be reoxidized with 8 a gas which is a lower temperature in which case a constant $\bar{c}_{\mathrm{p}}$ would overestimate the energy storage.

\section{2.2. Species Entropy}

Similar to determining the enthalpies of formation, the values of absolute species entropies must be determined to 11 obtain thermodynamic functions for species entropies in the solid. The method is best addressed by establishing the 12 total entropy of reaction from the equilibrium reaction expressions,

$$
\Delta S_{\mathrm{ox}}=\bar{s}_{\mathrm{O}_{\mathrm{O}}^{\times}}(T)+2 \bar{s}_{\mathrm{Mn}_{\mathrm{Mn}}^{\times}}(T)-\frac{1}{2} \bar{s}_{\mathrm{O}_{2(\mathrm{~g})}}(T)
$$

$$
-\bar{s}_{\mathrm{V}_{\mathrm{O}}}(T)-2 \bar{s}_{\mathrm{Mn}_{\mathrm{Mn}}^{\prime}}(T)
$$

13

$$
\Delta S_{\mathrm{dis}}=\bar{s}_{\mathrm{Mn}_{\mathrm{Mn}}^{\prime}}(T)+\bar{s}_{\mathrm{Mn}} \cdot \overline{\mathrm{Mn}}_{(T)}(T) \overline{\mathrm{Mn}}_{\mathrm{Mn}}^{\times}(T) .
$$

14 Here the entropies are taken to include the absolute, sensible, and ideal mixing components

$$
\bar{s}_{i}=\bar{s}_{\mathrm{f}, i}^{\circ}+\int_{T_{\mathrm{o}}}^{T} \frac{\bar{c}_{\mathrm{p}, i}(T)}{T} d T-R \ln \left(a_{i}\right) .
$$

15 The species $\mathrm{Mn}_{\mathrm{Mn}}^{\times}$and $\mathrm{V}_{\mathrm{O}}^{\bullet \bullet}$ are assumed to be the standard state and have an absolute entropy of zero at $T_{\circ}$, which 16 represents a shift in the absolute value from the typical absolute entropy of zero at $0 \mathrm{~K}$. Additionally, since the the 17 specific heats are required to satisfy $\sum_{i} v_{k, i} \bar{c}_{\mathrm{p}, i}(T)=0$, the sensible terms will all cancel resulting in

$$
\begin{aligned}
& \Delta S_{\mathrm{ox}}=\bar{s}_{\mathrm{f}, \mathrm{O}_{\mathrm{O}}^{\times}}^{\circ}-R \ln \left(\left[\mathrm{O}_{\mathrm{O}}^{\times}\right]_{\mathrm{L}}\right) \\
& -2 R \ln \left(\left[\mathrm{Mn}_{\mathrm{Mn}}^{\times}\right]_{\mathrm{L}}\right)-\frac{1}{2}\left[\bar{s}_{\mathrm{f}, \mathrm{O}_{2(\mathrm{~g})}}-R \ln \left(\frac{x_{\mathrm{O}_{2} p}}{p_{\circ}}\right)\right] \\
& +R \ln \left(\left[\mathrm{V}_{\mathrm{O}}^{\bullet \bullet}\right]_{\mathrm{L}}\right)-2\left[\bar{s}_{\mathrm{f}, \mathrm{Mn}}^{\circ}-R \ln \left(\left[\mathrm{Mn}_{\mathrm{Mn}}^{\prime}\right]_{\mathrm{L}}\right)\right]
\end{aligned}
$$




$$
\Delta S_{\mathrm{dis}}=\bar{s}_{\mathrm{f}, \mathrm{Mn}}^{\circ}-R \ln \left(\left[\mathrm{Mn}_{\mathrm{Mn}}^{\prime}\right]_{\mathrm{L}}\right)+\bar{s}_{\mathrm{f}, \mathrm{Mn}}^{\circ} \mathrm{Mn}^{\circ}
$$

$$
-R \ln \left(\left[\mathrm{Mn}_{\mathrm{Mn}}^{\bullet}\right]_{\mathrm{L}}\right)+2 R \ln \left(\left[\mathrm{Mn}_{\mathrm{Mn}}^{\times}\right]_{\mathrm{L}}\right) .
$$

1 Taking all of the species site concentrations to be at unit activity results in expressions for the standard state entropy 2 of reaction.

$$
\Delta S_{\mathrm{ox}}^{\circ}=\bar{s}_{\mathrm{f}, \mathrm{O}_{\mathrm{O}}^{\times}}^{\circ}-\frac{1}{2} \bar{s}_{\mathrm{f}, \mathrm{O}_{2(\mathrm{~g})}}-2 \bar{s}_{\mathrm{f}, \mathrm{Mn}}^{\circ} \mathrm{Mn}^{\prime}
$$

3

$$
\Delta S_{\mathrm{dis}}^{\circ}=\bar{s}_{\mathrm{f}, \mathrm{Mn}}^{\circ}{ }_{\mathrm{Mn}}^{\prime}+\bar{s}_{\mathrm{f}, \mathrm{Mn}}^{\circ}{ }_{\mathrm{Mn}}
$$

${ }_{4}$ The same assumption $\left(\bar{s}_{\mathrm{f}, \mathrm{Mn}}^{\circ}{ }_{\mathrm{Mn}}=\bar{s}_{\mathrm{f}, \mathrm{Mn}}^{\circ}{ }_{\mathrm{Mn}}\right)$ made for the enthalpy of charged manganese species can be used in the 5 entropy calculation to obtain expressions for the standard entropy of oxygen and manganese in the lattice relative to 6 oxygen in the gas phase.

$$
\begin{gathered}
\bar{s}_{\mathrm{f}, \mathrm{O}_{\mathrm{O}}^{\times}}^{\circ}=\Delta S_{\mathrm{ox}}^{\circ}+\frac{1}{2} \bar{s}_{\mathrm{f}, \mathrm{O}_{2(\mathrm{~g})}}^{\circ}+\Delta S_{\mathrm{dis}}^{\circ} \\
\bar{s}_{\mathrm{f}, \mathrm{Mn}_{\mathrm{Mn}}^{\circ}}^{\circ}=\bar{s}_{\mathrm{f}, \mathrm{Mn}}^{\circ} \cdot{ }_{\mathrm{Mn}}^{\circ}=\frac{1}{2} \Delta S_{\mathrm{dis}}^{\circ}
\end{gathered}
$$

8 The entropy of the individual species can now be written in terms of standard state entropy, sensible, and mixing 9 terms. Performing the integrals, using the approach to specific heat calculations that was developed for the enthalpy 10 functions, results in the following set of expressions

$$
\begin{aligned}
\bar{s}_{\mathrm{O}_{\mathrm{O}}^{\times}}(T)=\Delta S_{\mathrm{ox}}^{\circ}+\frac{1}{2} \bar{s}_{\mathrm{f}, \mathrm{O}_{2(\mathrm{~g})}}+\Delta S_{\mathrm{dis}}^{\circ}+\frac{5}{2} \frac{3 R}{\left[\mathrm{O}_{\mathrm{O}}^{\times}\right]_{\mathrm{L}}} \ln \left(T / T_{\mathrm{o}}\right) & \\
& +\frac{1}{2} \frac{\frac{1}{2}-\left[\mathrm{V}_{\mathrm{O}}^{\bullet \bullet}\right]_{\mathrm{L}}}{\left[\mathrm{O}_{\mathrm{O}}^{\times}\right]_{\mathrm{L}}}\left(\bar{s}_{\mathrm{O}_{2(\mathrm{~g})}}(T)-\bar{s}_{\mathrm{O}_{2(\mathrm{~g})}}^{\circ}\left(T_{\circ}\right)\right)-R \ln \left(\left[\mathrm{O}_{\mathrm{O}}^{\times}\right]_{\mathrm{L}}\right)
\end{aligned}
$$

11

$$
\bar{s}_{\mathrm{V}_{\mathrm{O}}}(T)=-R \ln \left(\left[\mathrm{V}_{\mathrm{O}}^{\bullet \bullet}\right]_{\mathrm{L}}\right)
$$

$$
\bar{s}_{i}(T)=3 R \ln \left(T / T_{\circ}\right)-R \ln \left(\left[X_{i}\right]_{\mathrm{L}}\right)
$$

$$
i \in\left\{\mathrm{Mn}_{\mathrm{Mn}}^{\times}, \mathrm{Ca}_{\mathrm{Ca}}^{\times}, \mathrm{Sr}_{\mathrm{Ca}}^{\times}\right\}
$$

12

13

$$
\begin{gathered}
\bar{s}_{\mathrm{Mn}_{\mathrm{Mn}}^{\prime}}(T)=\frac{1}{2} \Delta S_{\mathrm{dis}}^{\circ}+3 R \ln \left(T / T_{\circ}\right)-R \ln \left(\left[\mathrm{Mn}_{\mathrm{Mn}}^{\prime}\right]_{\mathrm{L}}\right) \\
\bar{s}_{\mathrm{Mn}_{\mathrm{Mn}}}(T)=\frac{1}{2} \Delta S_{\mathrm{dis}}^{\circ}+3 R \ln \left(T / T_{\circ}\right)-R \ln \left(\left[\mathrm{Mn}_{\mathrm{Mn}}^{\circ}\right]_{\mathrm{L}}\right)
\end{gathered}
$$


1 The total entropy of the solid on a mass basis can be expressed as

$$
s_{\mathrm{S}}\left(T,[\mathbf{X}]_{\mathrm{L}}\right)=\frac{1}{M\left(\left[\mathrm{~V}_{\mathrm{O}}^{\bullet \bullet}\right]_{\mathrm{L}}\right)} \sum_{i}\left[X_{i}\right]_{\mathrm{L}} \bar{s}_{i}\left(T,\left[X_{i}\right]_{\mathrm{L}}\right)
$$

2 using the species entropy expressions from above and a molar mass which is a function of the oxygen vacancy con3 centration. A plot of the total entropy of the solid for variations in $T$ and $p_{\mathrm{O}_{2}}$ where the point defect model has been 4 equilibrated is given in Fig. 3. As expected, the entropy of the solid phase increases with $T$. However, varying de-

5 pendencies on $p_{\mathrm{O}_{2}}$ are observed where entropy associated with defect concentration can cause entropy reductions or 6 increases with $p_{\mathrm{O}_{2}}$.

\section{2.3. Exergy Calculations}

$8 \quad$ The exergy analysis of systems implementing these material as a heat transfer fluid or oxygen carrier can be of 9 interest to identify the processes with the highest irreversibilities. The exergy or availability $(\psi)$ at any state for gas $10(g)$ or solid $(s)$ can be defined as,

$$
\psi_{\mathrm{g}(\mathrm{s})}=\left(h_{\mathrm{g}(\mathrm{s})}-h_{\mathrm{g}(\mathrm{s}) \circ}\right)-T_{\circ}\left(s_{\mathrm{g}(\mathrm{s})}-s_{\mathrm{g}(\mathrm{s}) \circ}\right)
$$

11 The specific enthalpy and entropy for the gas phase are evaluated as $h_{\mathrm{g}}=\sum_{i} y_{i} h_{i}(T)$ and $s_{\mathrm{g}}=\sum_{i} y_{i} s_{i}\left(T, p_{i}\right)$ for the state 12 point, and $h_{\mathrm{g} \circ}=\sum_{i} y_{i} h_{i}\left(T_{\circ}\right)$ and $s_{\mathrm{g} \circ}=\sum y_{i} s_{i}\left(T_{\circ}, p_{\circ, i}\right)$ for the reference condition. The reference condition activities are 13 taken to be the values of air at $50 \%$ relative humidity $\left(x_{\mathrm{N}_{2}}^{\circ}=0.7685, x_{\mathrm{O}_{2}}^{\circ}=0.2062, x_{\mathrm{CO}_{2}}^{\circ}=0.0004, x_{\mathrm{H}_{2} \mathrm{O}}^{\circ}=0.0156\right)[30]$.

14 If a species is present in the gas phase which contains chemical exergy $\left(\mathrm{CH}_{4}, \mathrm{CO}, \mathrm{H}_{2}\right)$, the enthalpy and entropy of the 15 standard state are taken to be the components of stoichiometric oxidation [31]. The specific enthalpy and entropy for 16 the solid phase are evaluated as $h_{\mathrm{S}}=\frac{1}{M\left(\left[\mathrm{~V}_{\mathrm{O}}^{\bullet \bullet}\right]_{\mathrm{L}}\right)} \sum_{i}\left[X_{i}\right]_{\mathrm{L}} h_{i}(T)$ and $s_{\mathrm{S}}=\frac{1}{M\left(\left[\mathrm{~V}_{\mathrm{O}}^{\bullet \bullet}\right]_{\mathrm{L}}\right)} \sum_{i}\left[X_{i}\right] s_{i}\left(T,\left[X_{i}\right]_{\mathrm{L}}\right)$ for the state point, 17 respectively. Where the specific enthalpy and entropy for the solid phase are evaluated as $h_{\mathrm{s} \circ}=\frac{1}{M\left(\left[\mathrm{~V}_{\mathrm{O}}^{\bullet}\right]_{\mathrm{L}}\right)} \sum_{i}\left[X_{i}\right]_{\mathrm{L}} h_{i}\left(T_{\circ}\right)$ 18 and $s_{\mathrm{S} \circ}=\frac{1}{M\left(\left[\mathrm{~V}_{\mathrm{O}}^{\bullet \bullet}\right]_{\mathrm{L}}\right)} \sum_{i}\left[X_{i}\right]_{\mathrm{L}} s_{i}\left(T_{\circ},\left[X_{i}\right]_{\mathrm{L}}^{\circ}\right)$ for the reference condition, respectively. The solid site concentrations at the 19 reference condition $\left(\left[X_{i}\right]_{\mathrm{L}}^{\circ}\right)$ must be thermodynamically consistent with the reference condition of the gas, which are so determined by solving the defect reaction equilibrium model at the reference temperature $\left(T_{\circ}=298.15 \mathrm{~K}\right)$, pressure ${ }_{21}\left(p_{\circ}=1 \mathrm{~atm}\right)$, and gas phase oxygen mole fraction $\left(x_{\mathrm{O}_{2}}^{\circ}\right)$.

\section{2.4. Relation to Partial Molar Properties}

23 Partial molar enthalpy $\left(\Delta H_{\mathrm{O}}\right)$ and entropy $\left(\Delta S_{\mathrm{O}}\right)$ change of oxygen are often reported in the literature either in 24 addition to or in place of a point defect model. The quantities can be calculated directly from experimental equilibrium 25 TGA or coulometric titration data by numerically evaluating the partial derivatives $[21,25,32]$, 


$$
\Delta H_{\mathrm{O}}=\bar{h}_{\mathrm{O}}-\bar{h}_{\mathrm{O}}^{\circ}=\left.\frac{R}{2} \frac{\partial \ln \left(p_{\mathrm{O}_{2}}\right)}{\partial(1 / T)}\right|_{\delta}
$$

1

$$
\Delta S_{\mathrm{O}}=\bar{s}_{\mathrm{O}}-\bar{s}_{\mathrm{O}}^{\circ}=-\left.\frac{R}{2} \frac{\partial T \ln \left(p_{\mathrm{O}_{2}}\right)}{\partial T}\right|_{\delta}
$$

2 Mizusaki et al. [25] related the point defect thermodynamic reaction parameters to the partial molar quantities through 3 a derivation considering a point defect model including an oxygen incorporation reaction and charge disproportiona4 tion reaction. Although the material investigated was $\mathrm{La}_{1-\mathrm{x}} \mathrm{Sr}_{\mathrm{x}} \mathrm{FeO}_{3-\delta}$, the general approach to relating the quantities 5 applies. For the present material $\mathrm{Ca}_{0.6} \mathrm{Sr}_{0.4} \mathrm{MnO}_{3-\delta}$ the quantities are related analytically as

$$
\begin{gathered}
\Delta H_{\mathrm{O}}=\Delta H_{\mathrm{ox}}^{\circ}-\frac{\partial\left[\mathrm{Mn}_{\mathrm{Mn}}^{\bullet}\right]_{\mathrm{L}}}{\partial\left[\mathrm{V}_{\mathrm{O}}^{\bullet \bullet}\right]_{\mathrm{L}}} \Delta H_{\mathrm{dis}}^{\circ} \\
\Delta S_{\mathrm{O}}=\Delta S_{\mathrm{ox}}^{\circ}-\frac{\partial\left[\mathrm{Mn}_{\mathrm{Mn}}^{\bullet}\right]_{\mathrm{L}}}{\partial\left[\mathrm{V}_{\mathrm{O}}^{\bullet \bullet}\right]_{\mathrm{L}}} \Delta S_{\mathrm{dis}}^{\circ}+\bar{s}_{\mathrm{O}, \mathrm{conf}} .
\end{gathered}
$$

7 The derivative of the manganese site polaron with respect to non-stoichiometry can be shown to be

$$
\frac{\partial\left[\mathrm{Mn}_{\mathrm{Mn}}^{\bullet}\right]_{\mathrm{L}}}{\partial\left[\mathrm{V}_{\mathrm{O}}^{\bullet}\right]_{\mathrm{L}}}=-\frac{1+\frac{\left[\mathrm{Mn}_{\mathrm{Mn}}^{\times}\right]_{\mathrm{L}}}{2\left[\mathrm{Mn}_{\mathrm{Mn}}^{\prime}\right]_{\mathrm{L}}}}{1+\frac{\left[\mathrm{Mn}_{\mathrm{Mn}}^{\times}\right]_{\mathrm{L}}}{4\left[\mathrm{Mn}_{\mathrm{Mn}}\right]_{\mathrm{L}}}+\frac{\left[\mathrm{Mn}_{\mathrm{Mn}}^{\times}\right]_{\mathrm{L}}}{4\left[\mathrm{Mn}_{\mathrm{Mn}}\right]_{\mathrm{L}}}}
$$

8 and configurational entropy can be shown to be

$$
\begin{aligned}
& \bar{s}_{\mathrm{O}, \mathrm{conf}}=R \frac{\partial\left[\mathrm{Mn}_{\mathrm{Mn}}^{\bullet}\right]_{\mathrm{L}}}{\partial\left[\mathrm{V}_{\mathrm{O}}^{\bullet \bullet}\right]_{\mathrm{L}}}\left(\ln \left(\left[\mathrm{Mn}_{\mathrm{Mn}}^{\bullet}\right]_{\mathrm{L}}\right)+1\right) \\
& +R \frac{\partial\left[\mathrm{Mn}_{\mathrm{Mn}}^{\times}\right]_{\mathrm{L}}}{\partial\left[\mathrm{V}_{\mathrm{O}}^{\bullet \bullet}\right]_{\mathrm{L}}}\left(\ln \left(\left[\mathrm{Mn}_{\mathrm{Mn}}^{\times}\right]_{\mathrm{L}}\right)+1\right) \\
& +R \frac{\partial\left[\mathrm{Mn}_{\mathrm{Mn}}^{\prime}\right]_{\mathrm{L}}}{\partial\left[\mathrm{V}_{\mathrm{O}}^{\bullet \bullet}\right]_{\mathrm{L}}}\left(\ln \left(\left[\mathrm{Mn}_{\mathrm{Mn}}^{\prime}\right]_{\mathrm{L}}\right)+1\right)+R \ln \left(\frac{\left[\mathrm{V}_{\mathrm{O}}^{\bullet \bullet}\right]_{\mathrm{L}}}{\left[\mathrm{O}_{\mathrm{O}}^{\times}\right]_{\mathrm{L}}}\right) .
\end{aligned}
$$

9 Alternatively, the thermodynamic functions, derived in the previous sections, can be implemented to calculate the 10 partial molar enthalpy and entropy change of oxygen from the thermodynamic definition

11

$$
\Delta H_{\mathrm{O}}=\left.\frac{\partial \bar{h}_{\mathrm{s}}}{\partial\left[\mathrm{O}_{\mathrm{O}}^{\times}\right]_{\mathrm{L}}}\right|_{p, T}-\frac{1}{2} \bar{h}_{\mathrm{O}_{2}(g)}^{\circ}
$$

$$
\Delta S_{\mathrm{O}}=\left.\frac{\partial \bar{s}_{\mathrm{S}}}{\partial\left[\mathrm{O}_{\mathrm{O}}^{\times}\right]_{\mathrm{L}}}\right|_{p, T}-\frac{1}{2} \bar{s}_{\mathrm{O}_{2}(g)}^{\circ}
$$


1 where the partial derivative can be evaluated numerically. If the functions have been properly formulated, the three

2 approaches for calculating $\Delta H_{\mathrm{O}}$ (Eqns. (40), (42), and (46)) and $\Delta S_{\mathrm{O}}$ (Eqns. (41), (43), and (47)) will yield the same ${ }_{3}$ value. Figures 4 and 5 compare the three approaches and demonstrate the agreement in the partial molar quantities.

${ }_{4}$ Interestingly, although the standard enthalpy and entropy of the defect reactions are taken to be independent of $\delta$ and

${ }_{5} T, \Delta H_{\mathrm{O}}$ and $\Delta S_{\mathrm{O}}$ are still functions of $\delta$ and $T$.

\section{3. Application to Simple Systems}

7 Demonstration and verification of the modeling approach is shown by applying the developed thermodynamic s functions to two thermochemical processes involving perovskite oxide redox cycles: 1) a thermochemical energy 9 storage subsystem for a concentrated solar power plant (Fig. 8) and 2) a plant for chemical-looping combustion of 10 methane (Fig. 11). The two systems have separate reactors for perovskite oxidation and reduction, although the re11 duction method is significantly different. For either system, the two reactors are modeled as continuously stirred tank 12 reactors (CSTR) where the products are thermodynamically equilibrated and the outlet temperature is specified to ${ }_{13}$ determine the heat release needed. Although the two systems represent significantly different processes, the gener14 alization of the material thermodynamic functions allows for a single formulation of the mass, species, and energy 15 balances, which are given for a CSTR in the following equations.

$$
\dot{m}_{\mathrm{s}, \text { in }}+\dot{m}_{\mathrm{ox}}=\dot{m}_{\mathrm{s}, \mathrm{out}}
$$

16

$$
\dot{m}_{\mathrm{g}, \text { in }}=\dot{m}_{\mathrm{ox}}+\dot{m}_{\mathrm{g}, \text { out }}
$$

17

$$
\begin{gathered}
y_{k, \text { in }} \dot{m}_{\mathrm{g}, \text { in }}=\dot{m}_{k, \text { ox }}+y_{k, \text { out }} \dot{m}_{\mathrm{g}, \text { out }}+M_{k} \sum_{j}^{N_{\mathrm{rxn}}} v_{k, j} \dot{r}_{j} \\
\dot{m}_{\mathrm{s}, \text { in }, \text { in }}+\dot{m}_{\mathrm{g}, \text { in }} h_{\mathrm{g}, \text { in }}=\dot{m}_{\mathrm{s}, \text { out }} h_{\mathrm{s}, \text { out }}+\dot{m}_{\mathrm{g}, \text { out }} h_{\mathrm{g}, \text { out }}+\dot{Q}_{\mathrm{out}}
\end{gathered}
$$

19 These balance equations form a closed system of equations when coupled with the equilibrium and site constraints 20 of the solid phase and equilibrium constraints of the gas phase (if gas phase chemical reactions are present). The 21 solid and gas phase mass balances (Eqns. (48) and (49)) include an oxidation term $\left(\dot{m}_{\mathrm{ox}}=\dot{m}_{\mathrm{O}_{2}, \mathrm{ox}}\right)$, which accounts for 22 oxygen gained by the solid phase and lost by the gas phase. The same term appears in the gas phase species balance ${ }_{23}$ (Eq. (50)) since only oxygen is exchanged between the phases. Finally, the energy balance (Eq. (51)) requires the ${ }_{24}$ products in both phases to be in thermochemical equilibrium $\left(T_{\mathrm{S}}=T_{\mathrm{g}}\right)$. Expressions for the reaction rates $\left(\dot{r}_{k}\right)$ are not ${ }_{25}$ necessary since they are evaluated implicitly from the equilibrium constraint of the gas phase species. Additionally, a 26 solid species balance is not explicitly evaluated, however, the solution is subject to site constraints, electroneutrality, ${ }_{27}$ and constrained reaction pathways. 
1 Although not necessary for the solution to the energy and mass balance problem, it is desirable to formulate balance 2 equations for entropy and exergy, as well to solve for the quantities of entropy generation $\left(\dot{S}_{\text {gen }}\right)$ and exergy destruction

$3\left(\dot{\Phi}_{\mathrm{des}}\right)$ in the reactors. If all of the balance equations and thermodynamic functions have been properly formulated, 4 the identity, $\dot{\Phi}_{\mathrm{des}}=T_{\mathrm{o}} \dot{S}_{\mathrm{gen}}$, should be either found from the solution to the entropy or exergy balance equations.

$$
\begin{aligned}
& \dot{m}_{\mathrm{s}, \text { in }} s_{\mathrm{s}, \text { in }}+\dot{m}_{\mathrm{g}, \text { in }} s_{\mathrm{g}, \text { in }}=\dot{m}_{\mathrm{s}, \text { out }} s_{\mathrm{s}, \text { out }} \\
& +\dot{m}_{\mathrm{g}, \text { out }} s_{\mathrm{g}, \text { out }}+\frac{\dot{Q}_{\text {out }}}{T_{\text {out }}}-\dot{S}_{\mathrm{gen}} \\
& \dot{m}_{\mathrm{s}, \text { in } \psi_{\mathrm{s}, \text { in }}+\dot{m}_{\mathrm{g}, \text { in }} \psi_{\mathrm{g}, \text { in }}=\dot{m}_{\mathrm{s}, \text { out }} \psi_{\mathrm{s}, \text { out }}}+\dot{m}_{\mathrm{g}, \text { out }} \psi_{\mathrm{g}, \text { out }}+\dot{Q}_{\text {out }}\left(1-\frac{T_{\circ}}{T_{\text {out }}}\right)+\dot{\Phi}_{\text {des }}
\end{aligned}
$$

\section{3.1. Measurement of the Heat of Reaction}

$6 \quad$ The enthalpies of reaction can be directly measured through the use of differential scanning calorimetry (DSC) 7 experiments. However, the individual heats of reaction cannot be independently measured where the measurable s quantity is the change in the partial molar enthalpy of oxygen $\left(\Delta H_{\mathrm{O}}\right)$. Alternatively, measurements of the heat of 9 reaction have been made through adiabatic calorimetry [26] and drop solution calorimetry [33]. Since these methods 1o involve oxidation reactions as well as variations in temperature, the measurable quantity is not directly related to $11 \Delta H_{\mathrm{O}}$. In order to demonstrate the measurable nature of $\Delta H_{\mathrm{O}}$ through DSC experiments, an isothermal reactor model 12 is developed where the products and reactants are forced to be the same temperature. The net heat release between 13 two equilibrium state points is calculated by the CSTR analysis and divided by the moles of oxygen gained by the 14 solid. The resulting values of heat release are plotted against $\Delta H_{\mathrm{O}}$ in Fig. 6 and shown to be in agreement indicating 15 the partial molar enthalpy change is a directly measurable quantity as long as the products and reactants are moved 16 between two equilibrated statepoints at the same temperature. This result is subject to the ability to measure the heat 17 released for a differentiable change in $\delta$ where $\dot{m}_{\mathrm{Ox}}$ approaches zero.

18 In addition to the isothermal calorimetry simulations, the reactants and products can be specified to be at different 19 temperatures giving rise to sensible energy in addition to the chemical component. The interest in perovskites for so thermochemical energy storage $[4,5,6]$ makes redox calculations quantifying the energy storage potential and resolv21 ing the contributions relevant for analysis. Plots of the sensible and total energy storage in temperature and oxygen 22 partial pressure space of the reactants where the products are held at 773K and 0.21 atm oxygen are given in Fig. 7. ${ }_{23}$ The chemical energy storage is the difference between the sensible and total plots. Non-stoichiometry data (Fig. 1) 
1 shows increased $\delta$ with increased $T$ and reduced $p_{\mathrm{O}_{2}}$. Higher reduction increases chemical energy at increased $T$ and 2 reduced $p_{\mathrm{O}_{2}}$. The sensible energy shows a linear dependence on temperature due to the near constant $\bar{c}_{\mathrm{p}}$ and a minor ${ }_{3}$ reduction at lower $p_{\mathrm{O}_{2}}$ due to increased $\delta$.

\section{3.2. Thermochemical Energy Storage}

$5 \quad$ Fig. 8 depicts the process flow diagram for a simple thermochemical energy storage subsystem. The perovskite ma6 terial is cyclically reduced and oxidized to store and release chemical energy respectively. Additionally, the operating 7 temperatures of the reduction and oxidation reactors can be varied to enable a sensible component of energy storage 8 due to temperature swings of the solid material. Insulated storage silos can be located between the reactors to store and 9 discharge solid particles on demand, which enables discrepancies between the heat supplied to the reduction reactor 10 and demanded by the oxidation reactor to be handled. This type of storage enables load-following and peaking plant 11 operations for concentrating solar power plants where the solar resource and grid-energy demand exhibit significantly 12 different diurnal characteristics. Large swings in $T$ and $\delta$ of the solid material allow for high values of specific energy 13 storage to be attained from a combination of sensible and chemical components. While changing temperature alone 14 will vary the non-stoichiometry of the material, higher values of non-stoichiometry can be attained in the reduction 15 reactor by supplying a low- $p_{\mathrm{O}_{2}}$ sweep gas such as nitrogen from a pressure swing adsorption system. The perovskite 16 material is reoxidized in air in the reactor/heat exchanger, thereby delivering thermal energy to a potential power cy17 cle. The efficiency definitions for first $\left(\eta_{\mathrm{I}}\right)$ and second $\left(\eta_{\mathrm{II}}\right)$ law analysis of the redox cycle are given as $\eta_{\mathrm{I}}=\frac{\dot{Q}_{\mathrm{ox}}}{\dot{Q}_{\text {red }}}$ 18 and $\eta_{\mathrm{II}}=\frac{\dot{\Phi}_{\mathrm{Q}, \mathrm{ox}}}{\Phi_{\mathrm{Q}, \text { red }}+\dot{\Phi}_{\mathrm{in}, \text { sweep }}}$, respectively. Since the inlet oxidation and sweep gas streams are at ambient temperature, the 19 first law efficiency is simply the ratio of thermal energy released by the oxidation reactor to thermal energy supplied to 20 the reduction reactor. However, the second law efficiency is the ratio of the exergy of the thermal energy released and ${ }_{21}$ supplied by the reactors in addition to the exergy of the sweep gas stream due to deviations from ambient composition. 22 The specific energy storage $\left(E_{\mathrm{st}}\right)$ has been defined by $E_{\mathrm{st}}=\frac{\dot{Q}_{\mathrm{ox}}}{\dot{m}_{\mathrm{s}, \mathrm{red}}}$ as the ratio of the heat supplied by the oxidation ${ }_{23}$ reactor to the mass flow rate of reduced perovskite $\left(\dot{m}_{\mathrm{s}, \mathrm{red}}\right)$.

${ }_{24}$ The thermodynamic analysis employs the CSTR approach presented previously for the oxidation and reduction ${ }_{25}$ reactors. The model inputs are the high and low storage temperatures, oxidizing and reducing gas composition, 26 temperature and flow rate, and the solid mass flow rate. The resulting statepoints, energy, and exergy flows are given ${ }_{27}$ in Fig. 8 for the nominal system conditions. The system achieves a high value of thermal efficiency $\left(\eta_{\mathrm{I}}=88.9 \%\right)$, ${ }_{28}$ primarily due to the presence of the recuperative heat exchangers. Energetic inefficiencies are only the result of 29 thermal energy being carried away by the sweep and oxidation gas leaving the recuperative heat exchangers, which 3о account for the approximately $70 \mathrm{~kW}$ difference in thermal energy supplied to the reduction reactor and removed from 31 the oxidation reactor. Alternatively, the exergetic efficiency of the system is much lower $\left(\eta_{\mathrm{II}}=62.6 \%\right)$ due to the 32 processes of heat exchange, mixing, and reaction which do not result in energy loss but do degrade the quality of 
1 energy. The exergetic efficiency of the system is further penalized by the drastic difference in operating temperatures 2 of the reduction and oxidation reactors where high-grade thermal energy must be provided to the reduction reactor and 3 the resulting product is lower grade thermal energy delivered by the oxidation reactor.

$4 \quad$ Although the CSTR analysis will almost always result in a lower performance than spatially resolved plug flow 5 models where heat is released over the entire range of high to low temperature, the result illustrates a fundamental 6 difficulty with thermochemical energy storage where cycling temperature is necessary and results in large exergy 7 destruction. The pie chart in Fig. 9 plots the exergy destruction and flows leaving the system as a fraction of the $s$ inlet exergy flows (reduction heat addition, sweep gas, and oxidation gas). Exergetic inefficiencies are the result of 9 the exhaust gases leaving the recuperative heat exchangers, heat transfer across a finite temperature difference, such 10 as in the recuperative heat exchangers, and due to entropy generation of the reduction and oxidation reactions within 11 the reactors. The exergy destruction in the oxidation reactor is almost twice that of the reduction reactor, which is 12 largely due to heat exchange through large temperature differences where high-grade thermochemical energy result in 13 low-grade thermal energy.

14 System performance in terms of efficiency and specific energy storage is displayed in Fig. 10 with variations in 15 the ratio of the sweep and oxidation gas flow rate to the solid flow rate. The competing effects between specific 16 storage and efficiency are displayed, where increasing the sweep gas flow rate results in achieving higher levels of 17 reduction and reoxidation in the reactors, however, a large amount of energy as well as exergy will leave the system 18 as exhaust with increased gas flow rates. Thus, a trade between $E_{\mathrm{st}}$ and $\eta$ is observed until a maximum in $E_{\mathrm{st}}$ is 19 encountered. The peak in the $E_{\mathrm{st}}$ plot is due to the exhaust heat loss overwhelming the sensible and chemical energy 20 storage of the solid particles. Thus, there is an optimal flow rate of oxidant for energy recovery to minimize exhaust ${ }_{21}$ losses. However, this result is subject to solid gas kinetic limitations and gas fluidization requirements. The increased 22 chemical reduction with increased sweep gas flow rate raises chemical energy storage, but the energy requirement of ${ }_{23}$ heating the additional oxidation and sweep gas results in a lower value of heat being supplied by the oxidation reactor. ${ }_{24}$ Additionally, the recuperative heat exchanger performance is observed to decrease with increasing levels of reduction ${ }_{25}$ due to the increased mass flow rate discrepancies resulting in large differences in the stream capacitance values for the 26 effectiveness-NTU calculation.

\section{3.3. Chemical-Looping Combustion}

28 Perovskites as oxygen carriers in chemical-looping combustion [? 1, 34] are of interest because oxidation of a 29 hydrocarbon fuel can occur with essentially pure oxygen. This facilitates $\mathrm{CO}_{2}$ sequestration without the complication 3о of $\mathrm{N}_{2}$ dilution. The chemical-looping combustion system (Fig. 11) implements a fuel reactor in place of the reduction 31 reactor of the thermochemical energy storage system. Preheated methane enters the fuel reactor along with the solid 32 perovskite in its oxidized state. Reduction of the perovskite material is a highly endothermic process, however, if the 
1 oxygen released participates in methane oxidation (Eq. (54)) the net process becomes slightly exothermic.

$$
\mathrm{CH}_{4}+2 \mathrm{O}_{2} \rightleftharpoons 2 \mathrm{H}_{2} \mathrm{O}+\mathrm{CO}_{2}
$$

2 The methane fuel provides a very low $p_{\mathrm{O}_{2}}$ to facilitate reduction and supply the energy necessary to drive the 3 endothermic perovskite reduction. The analysis assumes equilibrium of the complete methane oxidation reaction (Eq. ${ }_{4}$ (54)) to determine the unknown gas phase reaction rates in the CSTR analysis. Alternatively, a more complex Gibbs ${ }_{5}$ free energy minimization approach can be implemented to consider alternative reaction pathways and carbonaceous 6 species such as $\mathrm{CO}$, but for simplicity here, a single reaction equilibrium approach is implemented. The fuel and air 7 reactors are assumed to operate at the same temperature, such that thermal energy is removed from both reactors to 8 maintain the specified temperature. The mass flow rate of methane is varied such that the oxygen partial pressure 9 of the exhaust in the fuel reactor is $10^{-5} \mathrm{~atm}$ and the flow rate of air into the oxidation reactor is controlled such that 10 the exhaust contains $1 \%$ oxygen on a mole basis. The first and second law definitions of efficiency are given as ${ }_{11} \eta_{\mathrm{I}}=\frac{\dot{Q}_{\text {fuel }}+\dot{Q}_{\mathrm{air}}}{\dot{E}_{\text {in,fuel }}}$ and $\eta_{\mathrm{II}}=\frac{\dot{\Phi}_{\mathrm{Q}, \text { fuel }}+\dot{\Phi}_{\mathrm{Q}, \text { air }}}{\dot{\Phi}_{\text {in,fuel }}}$, respectively. The first law efficiency is the ratio of the heat supplied by the 12 fuel and air reactors to the lower heating value of the fuel where the second law definition of efficiency considers the 13 exergy of the same components ${ }^{1}$.

14 The results for the nominal system configuration are displayed in Fig. 11, which displays similarly high energetic 15 efficiencies $\left(\eta_{\mathrm{I}}=90.1 \%\right)$ to the thermochemical energy storage system. Additionally, a large reduction from the 16 energetic efficiency to the exergetic efficiency $\left(\eta_{\mathrm{II}}=66.4 \%\right)$ is observed due to the overall process of converting high 17 exergy chemical fuel to lower grade thermal energy. The pie chart given in Fig. 12 shows the exergy flows as a 18 fraction of the inlet exergy flows (fuel and air exergy), where the fuel and air heat transfer percentages will sum to the 19 value of the exergetic efficiency and all other values represent exergy destruction. The dominate exergy destruction 20 occurs in the fuel reactor during methane oxidation by reduction of the perovskite oxygen carrier. The next largest ${ }_{21}$ exergy destruction component is in the fuel exhaust, which contains sensible exergy as well as the exergy of species at 22 concentrations significantly higher than the reference composition.

${ }_{23}$ In this chemical-looping process, both the air and fuel reactors have exothermic reactions when operated at the ${ }_{24}$ same temperature. The exothermicity in the fuel reactor is the result of a relatively low enthalpy of oxidation of the ${ }_{25}$ solid relative to the methane. However, it has been suggested [2] that reduced enthalpy of oxidation could simplify 26 the system thermal management. Alternatively, the fuel reactor temperature could operated adiabatically where the 27 enthalpy difference of fuel oxidation and perovskite reduction is offset by a temperature increase. An adiabatic fuel ${ }_{28}$ reactor would simplify the heat rejection where only the air reactor would require a heat exchanger.

\footnotetext{
${ }^{1}$ The calculation of the second law efficiency for the nominal system conditions given in Fig. 11 would proceed as $\eta_{\mathrm{II}}=\frac{41.27 \mathrm{~kW}+102.0 \mathrm{~kW}}{215.5 \mathrm{~kW}}$
} 
1 The chemical-looping combustion system performance for variations in operating temperature is displayed in Fig.

2 13. The energetic and exergetic efficiencies show different dependencies on operating temperature where the exergetic ${ }_{3}$ efficiency increases and the energetic efficiency decreases with operating temperature. The drop in energetic efficiency 4 is due to the increased thermal energy in the exhaust stream. The exergy lost by the exhaust stream increases with 5 reactor temperature, but the higher operating temperature will increase the exergy of the heat supplied by the reactors,

6 which more than offsets the increased losses in the exhaust. Thus, exergetic efficiency increases slightly with operating 7 temperature. The swings in $\delta$ of the perovskite material, which determine the ability of the material to transport oxygen s between reactors, increases with operating temperature. Thus, increasing temperature decreases required solid flow 9 rates for a given fuel flow rate.

\section{3.4. Solar Fuel Production}

11 Perovskite oxides have also been under investigation in the field of solar fuel production [7, 8]. The material essen12 tially creates favorable thermodynamics for splitting water into hydrogen and oxygen such that it can occur at lower 13 temperature. However, a penalty is incurred in the form of requiring a heat rejection step and/or reduction sweep gas $14[35,36]$ to create state points which are thermodynamically favorable for perovskite reduction and oxidation via water 15 reduction. The thermodynamics of $\mathrm{Ca}_{0.6} \mathrm{Sr}_{0.4} \mathrm{MnO}_{3-\delta}$ are not ideal for this process, where the high temperature oxide 16 reduction must be more endothermic than the water dissociation reaction [37] for the process to generate any usable 17 amount of hydrogen. Although the thermodynamic model developed herein is generally applicable to perovskite ox18 ides, the $\mathrm{Ca}_{0.6} \mathrm{Sr}_{0.4} \mathrm{MnO}_{3-\delta}$ material is not applicable to solar fuel production due to the unfavorable thermodynamics. 19 Solar fuel modeling can benefit from the developed thermodynamic model in similar ways to that of energy storage 2o and chemical-looping combustion. Higher fidelity models will incorporate complex diffusion models based on point 21 defect thermodynamics such as the Nernst-Planck-Poisson (NPP) formulation [24], which captures the effects of 22 multiple charge defect conductors. In addition to the transport, a detailed surface kinetic formulation [38] requires 23 knowledge of the concentration of charge compensating species at the surface which our model incorporates. Such 24 higher-fidelity models require knowledge of individual species thermodynamics to resolve species transport, surface 25 kinetics and thermal energy transport.

\section{4. Conclusion}

27 Thermodynamic functions were developed for perovskite oxide materials based on point defect reaction thermo28 dynamics. The new thermodynamic modeling approach of perovskites improves upon past models by allowing for 29 proper energy partitioning between the gas and solid phases for the oxidation and reduction reactions in a redox cyзо cle. The modeling approach allows for equilibrium calculations, energy, entropy and exergy balances to be performed 31 with exact closure and agreement between the methods. The model is shown to track complex trends in measured 
1 non-stoichiometry data, specific heat capacity, and global heats of reaction with respect to changes in $T$ and $p_{\mathrm{O}_{2}}$. The

2 thermodynamic functions can be implemented in higher fidelity models considering reactions with finite rates between

3 solid and gas phases of differing temperature while maintaining thermodynamic consistency. Resolving defect con-

4 centrations also holds merit in a rigorous treatment of transport and surface kinetic analyses that cannot be captured

5 with global reaction thermodynamics.

6 The functional forms of the equations were verified against alternative methods for calculating the partial molar 7 enthalpy and entropy change of oxygen and the measurable heat of reaction. The calculation procedure was demon8 strated for the thermodynamic analysis of a thermochemical energy storage subsystem of a concentrating solar power 9 plant and a chemical-looping combustion plant. The results indicate the dominant irreversibilities are present in the 10 oxidation reactor of the thermochemical energy storage system. A parametric study to sweep gas flow rate revealed the 11 trade off between specific energy storage and efficiency where increasing flow rates of sweep gas result in increased re12 duction, however, the process heating requirements resulted in lower efficiencies. The dominate irreversibilities of the 13 chemical-looping combustion system are present in the fuel reactor. Additionally, differing trends in the exergetic and 14 energetic efficiencies of the chemical-looping combustion plant were identified where increases in temperature low15 ered energetic efficiencies and increased exergetic efficiencies. The modeling approach demonstrates the necessary 16 coupling of defect thermochemistry and system-level analysis to obtain a fundamental understanding of the individual 17 processes.

\section{5. Acknowledgments}

19 This research was preformed under a grant from the Department of Energy SunShot Initiative ELEMENTS pro2o gram (award \#DE-EE0006537). The authors would also like to thank CSM professors Dr. Ryan O'Hayre, Dr. Jinhua 21 Tong, and Dr. Robert Kee for helpful discussion on perovskite oxide defect chemistry and thermodynamics. 
22 Nomenclature

$c_{\mathrm{p}, i} \quad$ Specific heat of species $i\left(\mathrm{~kJ} \mathrm{kmol}^{-1} \mathrm{~K}^{-1}\right)$

$\Delta G_{k}^{\circ} \quad$ Standard Gibbs free energy of reaction $k\left(\mathrm{~kJ} \mathrm{kmol}^{-1}\right)$

$h_{i} \quad$ Enthalpy of species $i\left(\mathrm{~kJ} \mathrm{~kg}^{-1}\right)$

$\bar{h}_{i} \quad$ Enthalpy of species $i\left(\mathrm{~kJ} \mathrm{kmol}^{-1}\right)$

$\bar{h}_{\mathrm{f}, i}^{\circ} \quad$ Enthalpy of formation of species $i\left(\mathrm{~kJ} \mathrm{kmol}^{-1}\right)$

$\Delta H_{k}^{\circ} \quad$ Standard enthalpy of reaction $k\left(\mathrm{~kJ} \mathrm{kmol}^{-1}\right)$

$K_{\mathrm{p}, k} \quad$ Partial pressure equilibrium constant

$\dot{m} \quad$ Mass flow rate $\left(\mathrm{kg} \mathrm{s}^{-1}\right)$

$M \quad$ Molar mass $\left(\mathrm{kg} \mathrm{kmol}^{-1}\right)$

$\dot{Q} \quad$ Heat $(\mathrm{kW})$

$R \quad$ Ideal gas constant $\left(\mathrm{kJ} \mathrm{kmol}^{-1} \mathrm{~K}^{-1}\right)$

$s_{i} \quad$ Entropy of species $i\left(\mathrm{~kJ} \mathrm{~kg}^{-1}\right)$

$\bar{s}_{i} \quad$ Entropy of species $i\left(\mathrm{~kJ} \mathrm{kmol}^{-1}\right)$

$\bar{s}_{\mathrm{f}, i}^{\circ} \quad$ Absolute entropy of species $i\left(\mathrm{~kJ} \mathrm{kmol}^{-1}\right)$

$\dot{S}_{\text {gen }} \quad$ Entropy generation rate $(\mathrm{kW})$

$\Delta S_{k}^{\circ} \quad$ Standard entropy of reaction $k\left(\mathrm{~kJ} \mathrm{kmol}^{-1}\right)$

$T \quad$ Temperature (K)

$T_{\circ} \quad$ Reference temperature $(\mathrm{K})$

$x_{i} \quad$ Mole fraction of species $i$

$\left[X_{i}\right]_{\mathrm{L}} \quad$ Site concentration

$\left[X_{i}\right] \quad$ Molar concentration $\left(\mathrm{kmol} \mathrm{m}^{-3}\right)$

Greek

$v_{k, i} \quad$ Stoichiometric coefficient of species $i$ in reaction $k$

$\psi_{i} \quad$ Exergy (availability) of species $i\left(\mathrm{~kJ} \mathrm{~kg}^{-1}\right)$

$\dot{\Phi}_{\text {des }} \quad$ Exergy destruction rate $(\mathrm{kW})$

\section{References}

3 [1] Peter Hallberg, Dazheng Jing, Magnus Rydén, Tobias Mattisson, and Anders Lyngfelt. Chemical looping

$4 \quad$ combustion and chemical looping with oxygen uncoupling experiments in a batch reactor using spray-dried

$5 \quad \mathrm{CaMn}_{1-\mathrm{x}} \mathrm{M}_{\mathrm{x}} \mathrm{O}_{3-\delta}(\mathrm{M}=\mathrm{Ti}, \mathrm{Fe}, \mathrm{Mg})$ particles as oxygen carriers. Energy \& Fuels, 27(3):1473-1481, 2013. 
- [2] Magnus Rydén, Henrik Leion, Tobias Mattisson, and Anders Lyngfelt. Combined oxides as oxygen-carrier

2 [3] Nathan Galinsky, Amit Mishra, Jia Zhang, and Fanxing Li. $\mathrm{Ca}_{1-\mathrm{x}} \mathrm{A}_{\mathrm{x}} \mathrm{MnO}_{3}(\mathrm{~A}=\mathrm{Sr}$ and Ba $)$ perovskite based oxygen carriers for chemical looping with oxygen uncoupling (CLOU). Applied Energy, In Press:-, 2015.

[4] Kevin Albrecht and Robert Braun. Thermodynamic analysis of non-stoichiometric perovskites as a heat transfer fluid for thermochemical energy storage in concentrated solar power. Proceedings of ASME 2015 9th International Conference on Energy Sustainability, 2015.

[5] Sean M. Babiniec, Eric N. Coker, James E. Miller, and Andrea Ambrosini. Investigation of $\mathrm{La}_{\mathrm{x}} \mathrm{Sr}_{1-\mathrm{x}} \mathrm{Co}_{\mathrm{y}} \mathrm{M}_{1-\mathrm{y}} \mathrm{O}_{3-\delta}(\mathrm{M}=\mathrm{Mn}, \mathrm{Fe})$ perovskite materials as thermochemical energy storage media. Solar Energy, 118:451-459, 2015.

[6] Andrew Oles. Modeling of Falling-Particle Solar Receiver for Hydrogen Production and Thermochemcial Energy Storage. PhD thesis, University of Maryland, December 2014.

[7] Anthony H. McDaniel, Elisabeth C. Miller, Darwin Arifin, Andrea Ambrosini, Eric N. Coker, Ryan O'Hayre, William C. Chueh, and Jianhua Tong. Sr- and Mn-doped $\mathrm{LaAlO}_{3-\delta}$ for solar thermchemical $\mathrm{H}_{2}$ and $\mathrm{CO}$ production. Energy and Environmental Science, 6:2424-2428, 2013.

[8] Jonathan R. Scheffe, David Weibel, and Aldo Steinfeld. Lanthanum-strontium-manganese perovskites as redox materials for solar thermochemical splitting of $\mathrm{H}_{2} \mathrm{O}$ and $\mathrm{CO}_{2}$. Energy \& Fuels, 27(8):4250-4257, 2013.

[9] Cristina Dueso, Claire Thompson, and Ian Metcalfe. High-stability, high-capacity oxygen carriers: Iron oxideperovskite composite materials for hydrogen production by chemical looping. Applied Energy, In Press:-, 2015.

[10] Mehdi Jafarian, Maziar Arjomandi, and Graham J. Nathan. A hybrid solar and chemical looping combustion system for solar thermal energy storage. Applied Energy, 103:671-678, 2013.

[11] M. Rydén, A. Lyngfelt, and T. Mattisson. $\mathrm{CaMn}_{0.875} \mathrm{Ti}_{0.125} \mathrm{O}_{3}$ as oxygen carrier for chemical-looping combustion with oxygen uncoupling (CLOU)-experiments in a continuously operating fluidized-bed reactor system. International Journal of Greenhouse Gas Control, 5(2):356-366, 2011.

[12] M. Arjmand, R. F. Kooiman, M. Ryden, H. Leion, T. Mattisson, and A. Lyngfelt. Sulfur tolerance of $\mathrm{Ca}_{\mathrm{x}} \mathrm{Mn}_{1-\mathrm{y}} \mathrm{M}_{\mathrm{y}} \mathrm{O}_{3-\delta}(\mathrm{M}=\mathrm{Mg}, \mathrm{Ti})$ perovskite-type oxygen carriers in chemical-looping with oxygen uncoupling (CLOU). Energy \& Fuels, 28(2):1312-1324, 2014. material for chemical-looping with oxygen uncoupling. Applied Energy, 113:1924-1932, 2014. 
27 [13] A. Cabello, A. Abad, P. Gayan, L. F. de Diego, F. Garcia-Labiano, and J. Adánez. Effect of operating conditions $1 \quad$ and $\mathrm{H}_{2} \mathrm{~S}$ presence on the performance of $\mathrm{CaMg}_{0.1} \mathrm{Mn}_{0.9} \mathrm{O}_{3-\delta}$ perovskite material in chemical looping combustion $2 \quad$ (CLC). Energy \& Fuels, 28(2):1262-1274, 2014.

${ }_{3}$ [14] M. Kallen, M. Rydén, C. Dueso, T. Mattisson, and A. Lyngfelt. CaMn ${ }_{0.9} \mathrm{Mg}_{0.1} \mathrm{O}_{3-\delta}$ as oxygen carrier in a gas$4 \quad$ fired $10 \mathrm{kWth}$ chemical-looping combustion unit. Industrial \& Engineering Chemistry Research, 52(21):6923$5 \quad 6932,2013$.

6 [15] Yanguang Chen, Nathan Galinsky, Ziren Wang, and Fanxing Li. Investigation of perovskite supported composite $7 \quad$ oxides, for chemical looping conversion of syngas. Fuel, 134:521-530, 2014.

8 [16] A. Demont and S. Abanades. Solar thermochemical conversion of $\mathrm{CO}_{2}$ into fuel via two-step redox cycling of 9 non-stoichiometric Mn-containing perovskite oxides. Journal of Materials Chemistry A, 3(7):3536-3546, 2015.

10 [17] S. Stolen, E. Bakken, and C. E. Mohn. Oxygen-deficient perovskites: linking structure, energetics and ion $11 \quad$ transport. Physical Chemistry Chemical Physics, 8(4):429-447, 2006.

12 [18] A. M. Deml, V. Stevanovic, C. L. Muhich, C. B. Musgrave, and R. O’Hayre. Oxide enthalpy of formation 13 and band gap energy as accurate descriptors of oxygen vacancy formation energetics. Energy \& Environmental ${ }_{14} \quad$ Science, 7(6):1996-2004, 2014.

15 [19] M. H. R. Lankhorst and J. E. tenElshof. Thermodynamic quantities and defect structure of $\mathrm{La}_{0.6} \mathrm{Sr}_{0.4} \mathrm{Co}_{1-\mathrm{y}} \mathrm{Fe}_{\mathrm{y}} \mathrm{O}_{3-\delta}(\mathrm{y}=0-0.6)$ from high-temperature coulometric titration experiments. Journal of Solid $17 \quad$ State Chemistry, 130(2):302-310, 1997.

18 [20] Egil Bakken, Juliana Boerio-Goates, Tor Grande, Beate Hovde, Truls Norby, Lisbeth Rørmark, Rebecca Stevens, and Svein Stølen. Entropy of oxidation and redox energetics of $\mathrm{CaMnO}_{3-\delta}$. Solid State Ionics, 176:2261 - 2267, 202005 .

${ }_{21}^{21}$ [21] E. Bucher, W. Sitte, G.B. Caraman, V.A. Cherepanov, T.V. Aksenova, and M.V. Ananyev. Defect equilibria and partial molar properties of $(\mathrm{La}, \mathrm{Sr})(\mathrm{Co}, \mathrm{Fe}) \mathrm{O}_{3-\delta}$. Solid State Ionics, 177:3109 - 3115, 2006.

${ }_{23}$ [22] Ekaterina I. Goldyreva, Ilia A. Leonidov, Mikhail V. Patrakeev, Andrey V. Chukin, Ivan I. Leonidov, and Victor L. ${ }_{24}$ Kozhevnikov. Oxygen nonstoichiometry and defect equilibrium in electron doped $\mathrm{Ca}_{0.6-\mathrm{y}} \mathrm{Sr}_{0.4} \mathrm{La}_{\mathrm{y}} \mathrm{MnO}_{3-\delta}$. Journal of Alloys and Compounds, 638(0):44 - 49, 2015.

26 [23] E. I. Leonidova, I. A. Leonidov, M. V. Patrakeev, and V. L. Kozhevnikov. Oxygen non-stoichiometry, high${ }_{27} \quad$ temperature properties, and phase diagram of $\mathrm{CaMnO}_{3-\delta}$. Journal of Solid State Electrochemistry, 15(5):107128 1075, 2011. 
29 [24] Robert J. Kee, Huayang Zhu, Brett W. Hildenbrand, Einar Vøllestad, Michael D. Sanders, and Ryan P. O’Hayre.

$1 \quad$ Modeling the steady-state and transient response of polarized and non-polarized proton-conducting doped-

2 perovskite membranes. Journal of The Electrochemical Society, 160(3):F290-F300, 2013.

3 [25] Junichiro Mizusaki, Masafumi Yoshihiro, Shigeru Yamauchi, and Kazuo Fueki. Thermodynamic quantities and

4 defect equilibrium in the perovskite-type oxide solid solution $\mathrm{La}_{1-\mathrm{x}} \mathrm{Sr}_{\mathrm{x}} \mathrm{FeO}_{3-\delta}$. Journal of Solid State Chemistry,

$5 \quad 67(1): 1-8,1987$.

6 [26] Lisbeth Rørmark, Anne Beate Mørch, Kjell Wiik, Svein Stølen, and Tor Grande. Enthalpies of oxidation of

$7 \mathrm{CaMnO}_{3-\delta}, \mathrm{Ca}_{2} \mathrm{MnO}_{3-\delta}$ and $\mathrm{SrMnO}_{3-\delta}$ - deduced redox properties. Chemistry of Materials, 13(11):4005-

$8 \quad 4013,2001$.

9 [27] Egil Bakken, Truls Norby, and Svein Stolen. Redox energetics of perovskite-related oxides. Journal of Materials Chemistry, 12:317-323, 2002.

11 [28] S.A. Klein. Engineering equation solver, 2014.

12 [29] Stanley I. Sandler. An Introduction to Applied Statistical Thermodynamics. John Wiley \& Sons, Inc., 2011.

13 [30] Eric W. Lemmon, Richard T Jacobsen, Steven G. Penoncello, and Daniel G. Friend. Thermodynamic properties of air and mixtures of nitrogen, argon, and oxygen from 60 to $2000 \mathrm{~K}$ at pressures to $2000 \mathrm{MPa}$. Journal of Physical and Chemical Reference Data, 29(3):331-385, 2000.

16 [31] Michael J. Moran and Howard N. Shapiro. Fundamentals of Engineering Thermodynamics. Wiley, 6th edition, 2007.

18 [32] M.-B. Choi, D.-K. Lim, E.D. Wachsman, and S.-J. Song. Oxygen nonstoichiometry and chemical expansion of mixed conducting $\mathrm{La}_{0.1} \mathrm{Sr}_{0.9} \mathrm{Co}_{0.8} \mathrm{Fe}_{0.2} \mathrm{O}_{3-\delta}$. Solid State Ionics, 221:22-27, 2012.

2o [33] Jihong Cheng and Alexandra Navrotsky. Energetics of $\mathrm{La}_{1-\mathrm{x}} \mathrm{A}_{\mathrm{x}} \mathrm{CrO}_{3-\delta}$ perovskites ( $\mathrm{A}=\mathrm{Ca}$ or $\mathrm{Sr}$ ). Journal of $21 \quad$ Solid State Chemistry, 178(1):234 - 244, 2005.

22 [34] E. Ksepko. Perovskite-type sr(mn1-x ni-x)o-3 materials and their chemical-looping oxygen transfer properties. International Journal of Hydrogen Energy, 39(15):8126-8137, 2014.

24 [35] J. Lapp, J.H. Davidson, and W. Lipiński. Efficiency of two-step solar thermochemical non-stoichiometric redox cycles with heat recovery. Energy, 37(1):591 - 600, 2012.

26 [36] Roman Bader, Luke J. Venstrom, Jane H. Davidson, and Wojciech Lipiński. Thermodynamic analysis of isothermal redox cycling of ceria for solar fuel production. Energy \& Fuels, 27(9):5533-5544, 2013. 
28 [37] James E. Miller, Mark D. Allendorf, Richard B. Diver, Lindsey R. Evans, Nathan P. Siegel, and John N. Stuecker.

$1 \quad$ Metal oxide composites and structures for ultra-high temperature solar thermochemical cycles. Journal of Mate$2 \quad$ rials Science, 43(14):4714-4728, 2008.

3 [38] S. B. Adler, X. Y. Chen, and J. R. Wilson. Mechanisms and rate laws for oxygen exchange on mixed-conducting $4 \quad$ oxide surfaces. Journal of Catalysis, 245(1):91-109, 2007. 


\section{${ }_{5}$ List of Figures}

1 1. Oxygen site concentration $\left(\left[\mathrm{O}_{\mathrm{O}}^{\times}\right]_{\mathrm{L}}=3-\delta\right)$ from thermodynamic equilibrium calculations based on the defect 2 model and thermodynamic parameters of Goldyreva et al. [22] for $\mathrm{Ca}_{0.6} \mathrm{Sr}_{0.4} \mathrm{MnO}_{3-\delta}$

3 2. Total enthalpy of the solid $\left(h_{\mathrm{s}}\right)$ for $\mathrm{Ca}_{0.6} \mathrm{Sr}_{0.4} \mathrm{MnO}_{3-\delta}$ as a function of temperature and oxygen partial pressure $4 \quad$ with the point defects equilibrated

5 3. Total entropy of the solid $\left(s_{\mathrm{s}}\right)$ for $\mathrm{Ca}_{0.6} \mathrm{Sr}_{0.4} \mathrm{MnO}_{3-\delta}$ as a function of temperature and oxygen partial pressure $6 \quad$ with the point defects equilibrated

7 4. Partial molar enthalpy $\left(\Delta H_{\mathrm{O}}\right)$ change of oxygen for $\mathrm{Ca}_{0.6} \mathrm{Sr}_{0.4} \mathrm{MnO}_{3-\delta}$ at various temperatures as a function of $8 \quad$ non-stoichiometry $\left(\delta=\left[\mathrm{V}_{\mathrm{O}}^{\bullet \bullet}\right]_{\mathrm{L}}\right)$ calculated by functional methods given in Eqns. (40), (42), and (46)

9 5. Partial molar entropy $\left(\Delta S_{\mathrm{O}}\right)$ change of oxygen for $\mathrm{Ca}_{0.6} \mathrm{Sr}_{0.4} \mathrm{MnO}_{3-\delta}$ at various temperatures as a function of non-stoichiometry $\left(\delta=\left[\mathrm{V}_{\mathrm{O}}^{\bullet \bullet}\right]_{\mathrm{L}}\right)$ calculated by functional methods given in Eqns. (41), (43), and (47)

6. Measurable heat of oxidation reaction by isothermal oxidation of the sample in a CSTR simulation compared to the partial molar enthalpy change of oxygen

7. Breakdown of energy storage capability of $\mathrm{Ca}_{0.6} \mathrm{Sr}_{0.4} \mathrm{MnO}_{3-\delta}$ where isobaric curves of sensible and total energy are given as a function of storage temperature of reactants where the product temperature is held at $773 \mathrm{~K}$ and $0.21 \mathrm{~atm}$ oxygen

8. Thermochemical energy storage subsystem process flow diagram with the energy and exergy flows at the nominal statepoints $\left(\frac{\dot{m}_{\mathrm{g}}}{\dot{m}_{\mathrm{s}}}=0.75, T_{\text {red }}=1273 \mathrm{~K}, T_{\mathrm{ox}}=673 \mathrm{~K}\right)$

9. Thermochemical energy storage subsystem exergy loss or destruction breakdown at the nominal condition

10. Specific energy storage, energetic and exergetic efficiency as a function of the sweep and oxidation gas flow rates for the thermochemical energy storage subsystem $\left(T_{\text {red }}=673 \mathrm{~K}, T_{\text {ox }}=1373 \mathrm{~K}\right)$

11. Chemical looping combustion system process flow diagram with the energy and exergy flows at the nominal statepoints $\left(T=1275 \mathrm{~K}, p_{\mathrm{O}_{2}, \text { fuel }}=10^{-5} \mathrm{~atm}, p_{\mathrm{O}_{2}, \mathrm{air}}=0.01 \mathrm{~atm}\right)$

12. Chemical-looping combustion exergy loss or destruction at the nominal statepoint

13. Energetic and exergetic efficiency as a function of the operating temperature of the fuel and air reactors for the chemical looping combustion system $\left(p_{\mathrm{O}_{2}, \text { fuel }}=10^{-5} \mathrm{~atm}, p_{\mathrm{O}_{2}, \text { air }}=0.01 \mathrm{~atm}\right)$ 


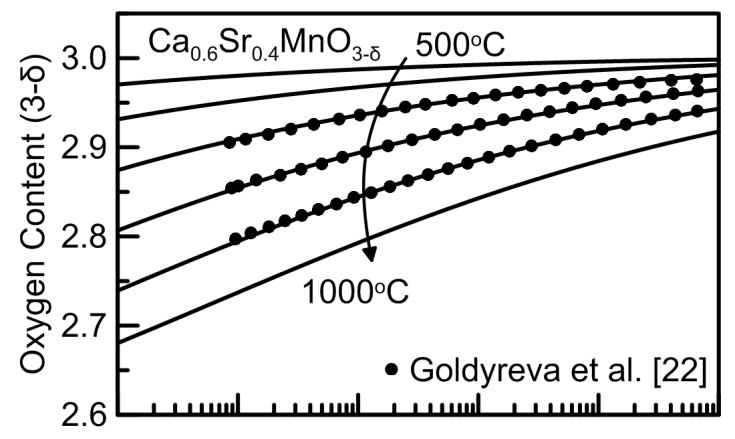

Figure 1: Oxygen site concentration $\left(\left[\mathrm{O}_{\mathrm{O}}^{\times}\right]_{\mathrm{L}}=3-\delta\right)$ from thermodynamic equilibrium calculations based on the defect model and thermodynamic parameters of Goldyreva et al. [22] for $\mathrm{Ca}_{0.6} \mathrm{Sr}_{0.4} \mathrm{MnO}_{3-\delta}$ 


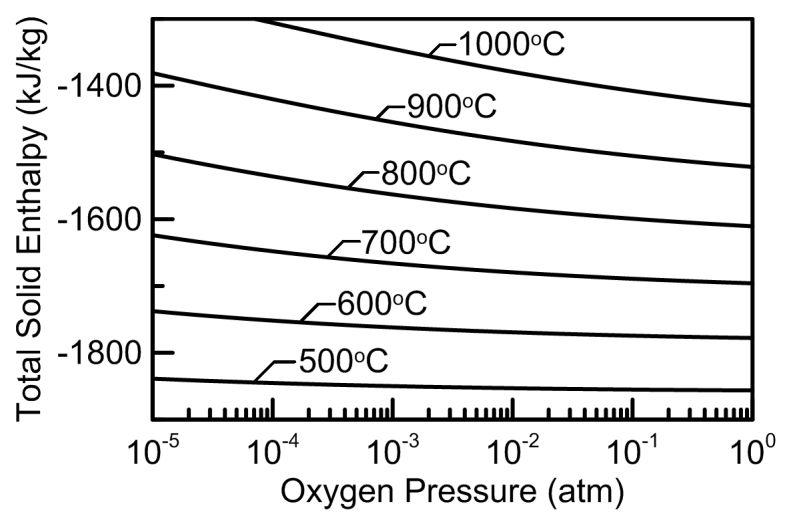

Figure 2: Total enthalpy of the solid $\left(h_{\mathrm{s}}\right)$ for $\mathrm{Ca}_{0.6} \mathrm{Sr}_{0.4} \mathrm{MnO}_{3-\delta}$ as a function of temperature and oxygen partial pressure with the point defects equilibrated 


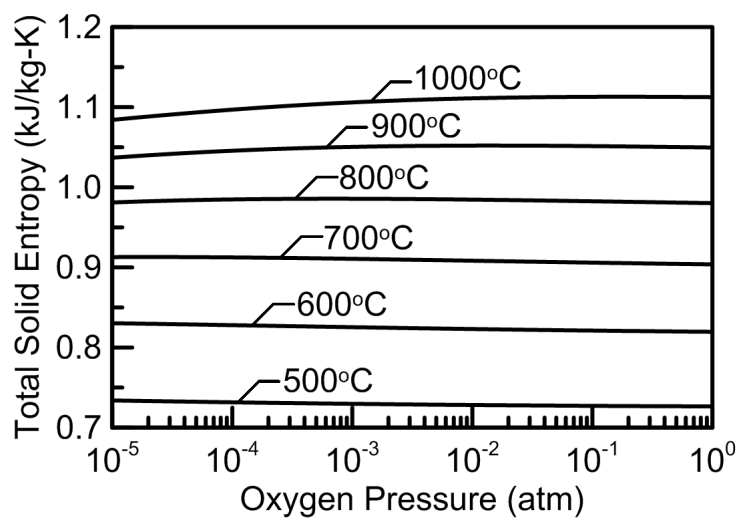

Figure 3: Total entropy of the solid $\left(s_{\mathrm{S}}\right)$ for $\mathrm{Ca}_{0.6} \mathrm{Sr}_{0.4} \mathrm{MnO}_{3-\delta}$ as a function of temperature and oxygen partial pressure with the point defects equilibrated 


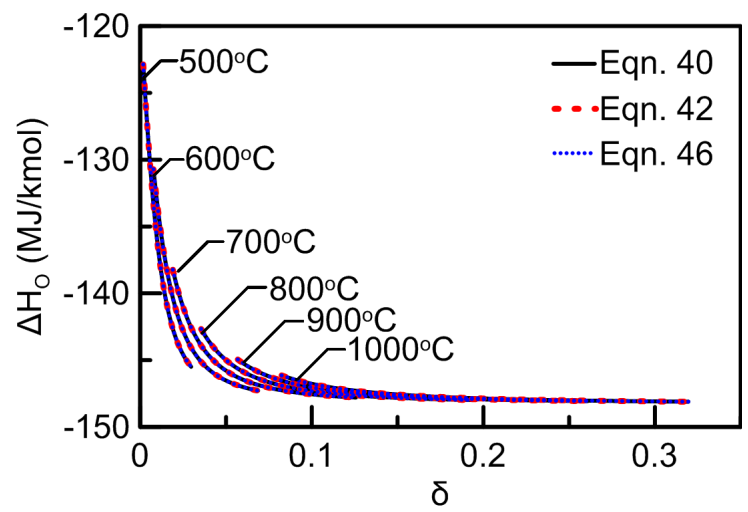

Figure 4: Partial molar enthalpy $\left(\Delta H_{\mathrm{O}}\right)$ change of oxygen for $\mathrm{Ca}_{0.6} \mathrm{Sr}_{0.4} \mathrm{MnO}_{3-\delta}$ at various temperatures as a function of non-stoichiometry $\left(\delta=\left[\mathrm{V}_{\mathrm{O}}^{\bullet \bullet}\right]_{\mathrm{L}}\right)$ calculated by functional methods given in Eqns. (40), (42), and (46) 


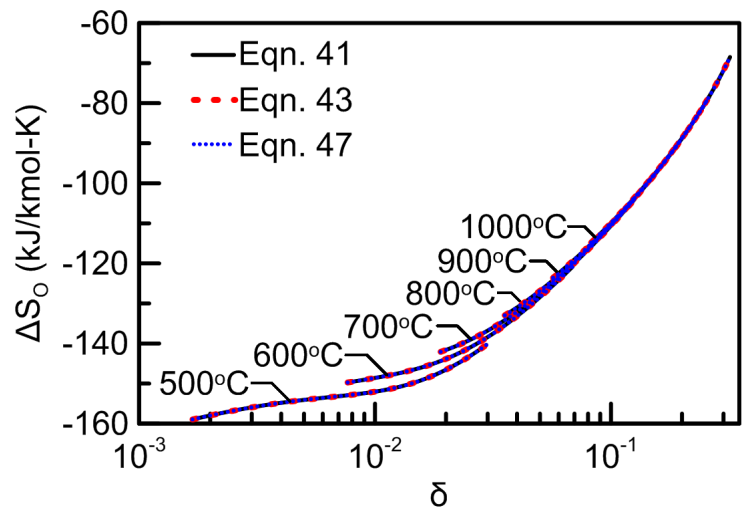

Figure 5: Partial molar entropy $\left(\Delta S_{\mathrm{O}}\right)$ change of oxygen for $\mathrm{Ca}_{0.6} \mathrm{Sr}_{0.4} \mathrm{MnO}_{3-\delta}$ at various temperatures as a function of non-stoichiometry $\left(\delta=\left[\mathrm{V}_{\mathrm{O}}^{\bullet \bullet}\right]_{\mathrm{L}}\right)$ calculated by functional methods given in Eqns. (41), (43), and (47) 


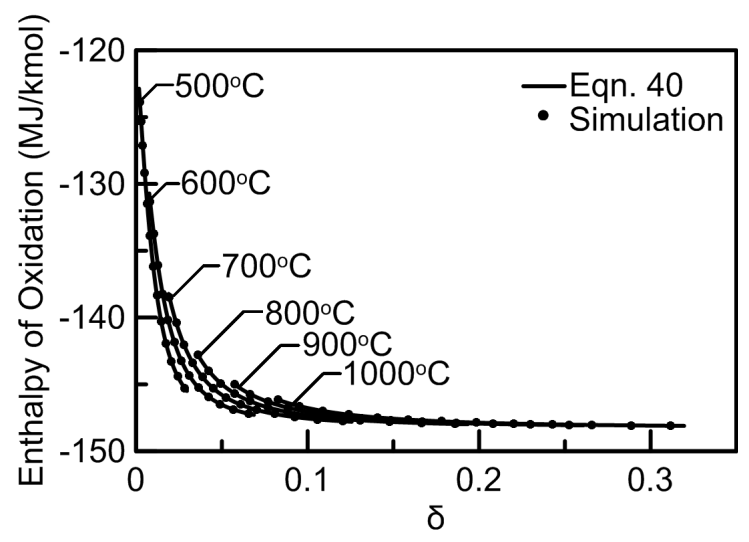

Figure 6: Measurable heat of oxidation reaction by isothermal oxidation of the sample in a CSTR simulation compared to the partial molar enthalpy change of oxygen 


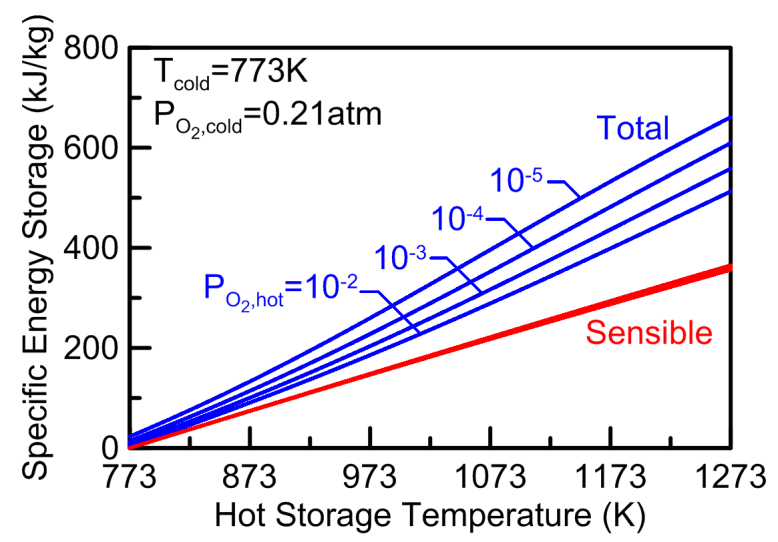

Figure 7: Breakdown of energy storage capability of $\mathrm{Ca}_{0.6} \mathrm{Sr}_{0.4} \mathrm{MnO}_{3-\delta}$ where isobaric curves of sensible and total energy are given as a function of storage temperature of reactants where the product temperature is held at $773 \mathrm{~K}$ and 0.21 atm oxygen 


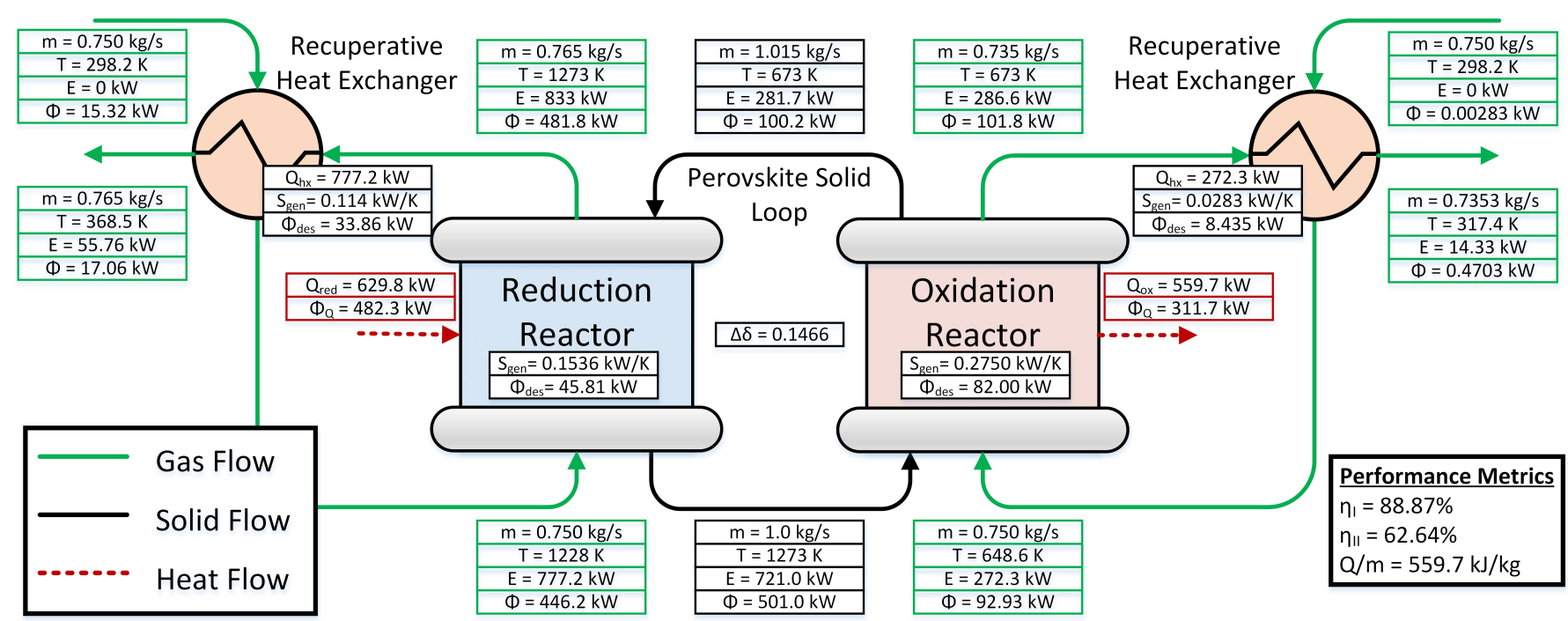

Figure 8: Thermochemical energy storage subsystem process flow diagram with the energy and exergy flows at the nominal statepoints $\left(\frac{\dot{m}_{\mathrm{g}}}{\dot{m}_{\mathrm{s}}}=0.75\right.$, $T_{\text {red }}=1273 \mathrm{~K}, T_{\mathrm{ox}}=673 \mathrm{~K}$ ) 


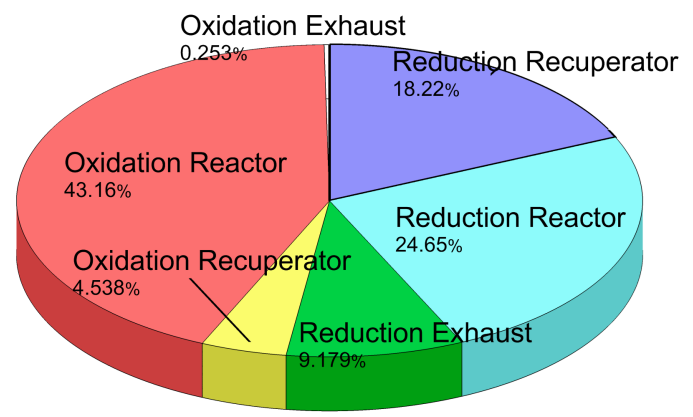

Figure 9: Thermochemical energy storage subsystem exergy loss or destruction breakdown at the nominal condition 


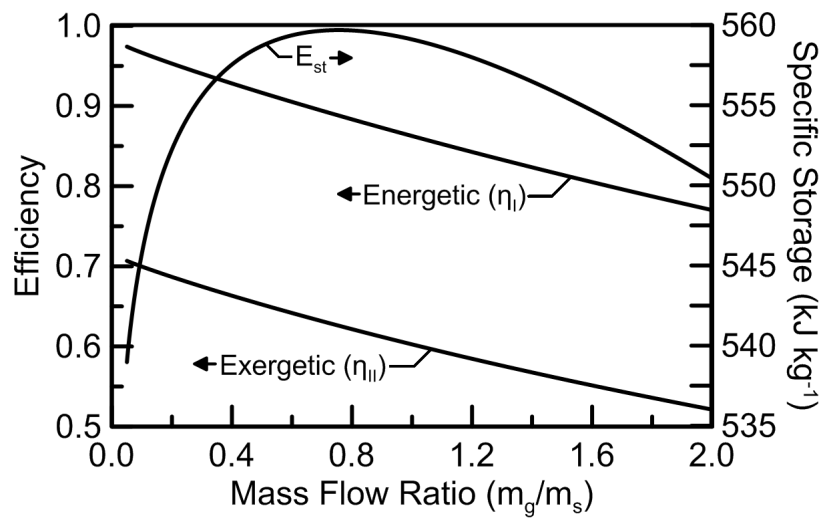

Figure 10: Specific energy storage, energetic and exergetic efficiency as a function of the sweep and oxidation gas flow rates for the thermochemical energy storage subsystem $\left(T_{\text {red }}=673 \mathrm{~K}, T_{\mathrm{ox}}=1373 \mathrm{~K}\right)$ 


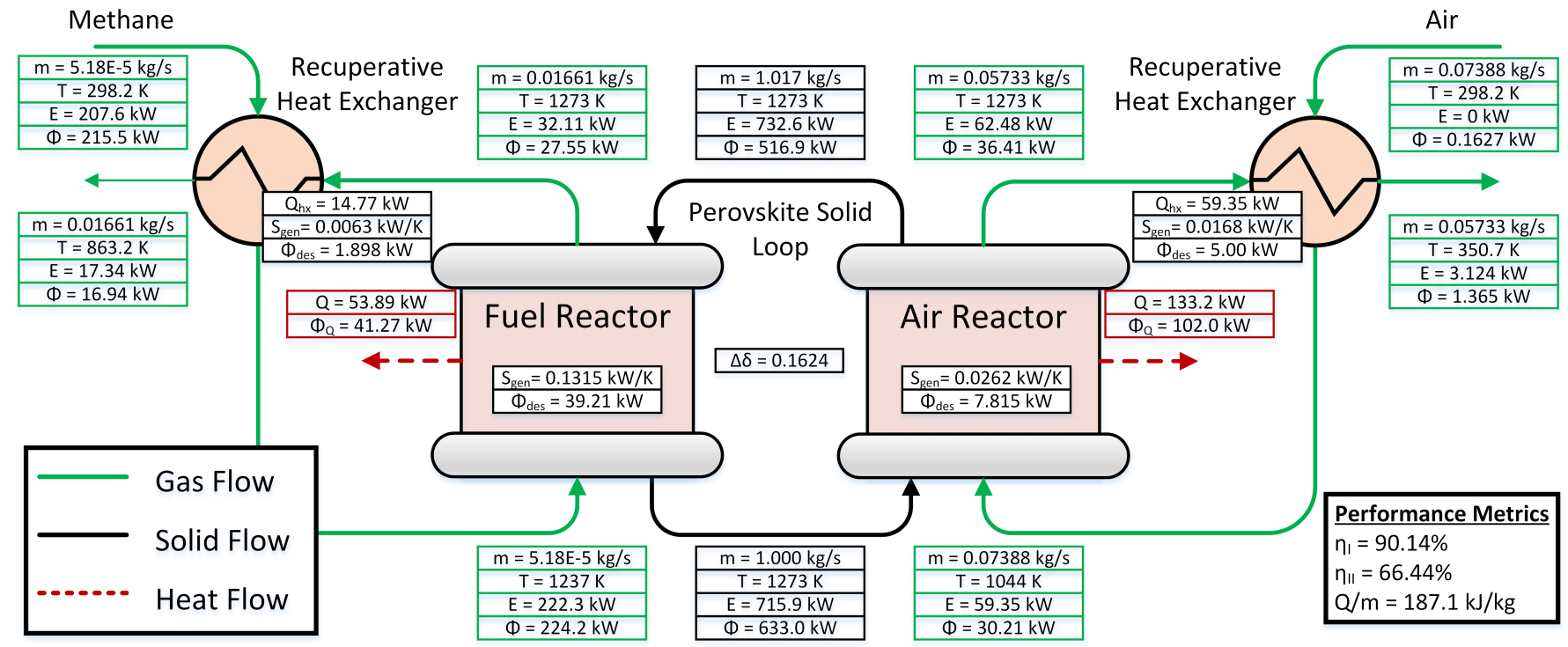

Figure 11: Chemical looping combustion system process flow diagram with the energy and exergy flows at the nominal statepoints ( $T=1275 \mathrm{~K}$, $\left.p_{\mathrm{O}_{2}, \text { fuel }}=10^{-5} \mathrm{~atm}, p_{\mathrm{O}_{2}, \text { air }}=0.01 \mathrm{~atm}\right)$ 


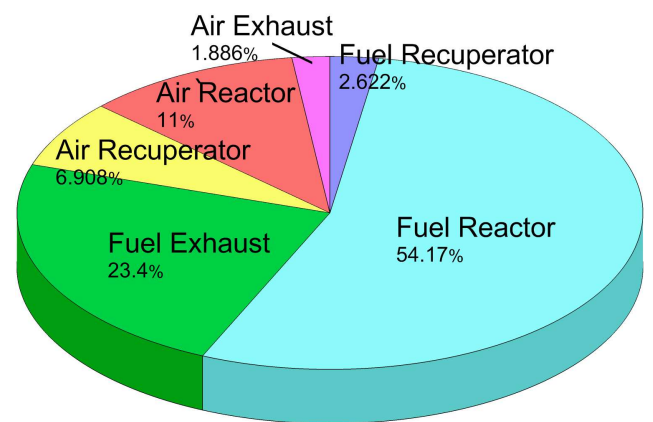

Figure 12: Chemical-looping combustion exergy loss or destruction at the nominal statepoint 


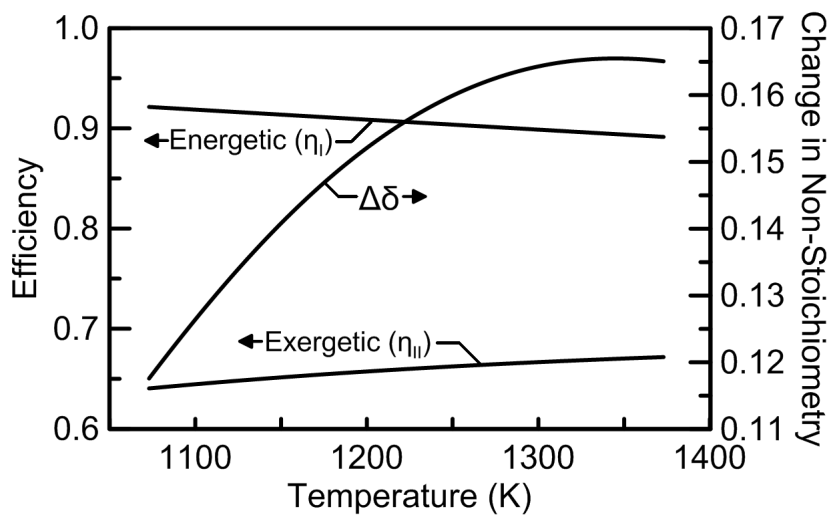

Figure 13: Energetic and exergetic efficiency as a function of the operating temperature of the fuel and air reactors for the chemical looping combustion system $\left(p_{\mathrm{O}_{2}, \text { fuel }}=10^{-5} \mathrm{~atm}, p_{\mathrm{O}_{2}, \text { air }}=0.01 \mathrm{~atm}\right)$ 


\section{${ }_{26}$ List of Tables}

1 1. Thermodynamic parameters of the defect model for $\mathrm{Ca}_{0.6} \mathrm{Sr}_{0.4} \mathrm{MnO}_{3-\delta}$ [22] 
Table 1: Thermodynamic parameters of the defect model for $\mathrm{Ca}_{0.6} \mathrm{Sr}_{0.4} \mathrm{MnO}_{3-\delta}$ [22]

\begin{tabular}{lrl}
\hline Parameter & Value & Units \\
\hline$\Delta H_{\mathrm{oX}}^{\circ}$ & -148.2 & $\mathrm{~kJ} \mathrm{~mol}^{-1}$ \\
$\Delta S_{\mathrm{ox}}^{\circ}$ & -60.4 & $\mathrm{~J} \mathrm{~mol}^{-1} \mathrm{~K}^{-1}$ \\
$\Delta H_{\text {dis }}^{\circ}$ & 28.8 & $\mathrm{~kJ} \mathrm{~mol}^{-1}$ \\
$\Delta S_{\text {dis }}^{\circ}$ & -33.9 & $\mathrm{~J} \mathrm{~mol}^{-1} \mathrm{~K}^{-1}$ \\
\hline
\end{tabular}

